\title{
Wpływ redukcji modelu układu nośnego pojazdu na jego charakterystyki własne
}

\begin{abstract}
Redukcja modelu układu nośnego pojazdu, poddanego analizie za pomoca metody elementów skończonych, jest stosowana $w$ celu estymacji istotnych dla badanego układu częstotliwości drgań własnych i odpowiadajacych im postaci. Wybór metody redukcji decyduje o jakości wyników dynamicznej analizy układu. W pracy przeprowadzono badania numeryczne $w$ zakresie oceny skuteczności wybranych metod redukcji modelu $w$ rozwiqzywaniu uogólnionego zagadnienia własnego dla przyjętego dyskretnego modelu uktadu nośnego.
\end{abstract}

\section{Wprowadzenie}

W analizie konstrukcji nośnej, prowadzonej za pomocą elementów skończonych, liczba stopni swobody układu osiaga dziesiątki tysięcy. Wyznaczenie częstotliwości drgań własnych oraz odpowiadających im postaci jest dla układu o tak znacznych wymiarach niecelowe. Konieczny jest wybór stopni swobody o podstawowym znaczeniu dla analizy badanego układu. Związane to jest $\mathrm{z}$ wyznaczeniem ograniczonej liczby najniższych częstotliwości drgań własnych i odpowiadającym im postaci. Procedurę związaną $\mathrm{z}$ takim działaniem nazwano redukcją układu [2].

Strategia redukcji w rozwiązaniu uogólnionego zagadnienia własnego polega na przyjęciu podstawowych stopni swobody (master), istotnych dla oceny charakterystyk własnych układu, oraz pomocniczych stopni swobody układu (slave), które w modelu zostają pominięte.

Guyan [4] jako pierwszy zaproponował metodę statycznej redukcji układu, w której nie został uwzględniony wpływ składników bezwładnościowych modelu. Dynamiczna redukcja została zaproponowana $\mathrm{w}$ pracach [3 i 6]. Ze względu na zależność stosowanej $\mathrm{w}$ procesie redukcji macierzy transformacji od częstotliwości drgań układu, zaproponowano iteracyjne metody wyznaczania macierzy transformacji oraz zredukowanych postaci macierzy sztywności i bezwładności [7 i 8].

W artykule przeprowadzono badania numeryczne dyskretnego modelu układu nośnego pojazdu, których celem było określenie jakości stosowanych metod redukcji modelu odnośnie do wartości charakterystyk własnych $\mathrm{w}$ postaci częstotliwości i postaci drgań własnych. Badaniom poddano również wpływ sposobu redukcji układu na związki między wymuszeniem a odpowiedzią układu charakteryzowane zerami transmitancji [1 i 5 ].

Przedstawiono cztery metody przeprowadzenia redukcji modelu układu. Związane są one z odmiennym podejściem do tworzenia macierzy transformacji układu. W zależności od procedury tworzenia macierzy transformacji, wprowadzono ich podział na metody jednokrokowe, dwukrokowe i wielokrokowe.
$\mathrm{W}$ metodach jednokrokowych generowana jest macierz transformacji, która następnie wykorzystywana jest do wyznaczenia zredukowanych macierzy sztywności i bezwładności. W metodach dwukrokowych wartości uzyskane za pomocą metody jednokrokowej przyjmowane sa jako pierwotne estymacje zredukowanego układu, a następnie wprowadzane są składniki kompensujące pominięte elementy bezwładnościowe. $\mathrm{W}$ metodach wielokrokowych stosowane są procedury iteracyjne dla wyznaczenia macierzy transformacji oraz zredukowanych macierzy sztywności i bezwładności.

\section{Istota redukcji dyskretnego modelu układu nośnego}

Równanie ruchu dyskretnego, liniowego, zachowawczego, stacjonarnego modelu układu mechanicznego o $n$ stopniach swobody przedstawiono w postaci:

$$
\mathbf{M} \ddot{\mathbf{q}}+\mathbf{K q}=\mathbf{B f}
$$

a równanie wyjść jako:

$$
\mathbf{y}=\mathbf{D q}
$$

gdzie:

q, $\ddot{\mathbf{q}}$ - wektory współrzędnych i przyspieszeń uogólnionych $\left(\mathbf{q} \in \mathfrak{R}^{n \times 1}\right)$,

$\mathbf{f}$ - wektor wymuszeń w postaci sił $\left(\mathbf{f} \in \mathfrak{R}^{r \times 1}\right)$,

$\mathbf{y}$ - wektor wielkości mierzonych w postaci przemieszczeń $\left(\mathbf{y} \in \mathfrak{R}^{p \times 1}\right)$,

$\mathbf{M}, \mathbf{K}$ - macierze bezwładności i sztywności

$\left(\mathbf{M}, \mathbf{K} \in \mathfrak{R}^{n \times n}\right) \quad$ spełniające warunki:

$$
\mathbf{M}=\mathbf{M}^{T}>0, \mathbf{K}=\mathbf{K}^{T} \geq 0,
$$

$\mathbf{B}$ - macierz wejść rzędu $r\left(\mathbf{B} \in \mathfrak{R}^{n \times r}\right)$,

$\mathbf{D}$ - macierz wyjść rzędu $p \times n\left(\mathbf{D} \in \mathfrak{R}^{p \times r}\right)$.

W celu przeprowadzenia analizy drgań własnych układu przyjęto zerową macierz wejść $(\mathbf{B}=\mathbf{0})$. Równania opisujące uogólnione zagadnienie własne mają postać:

gdzie:

$$
\mathbf{K} \Psi=\mathbf{M} \Psi \Lambda
$$


$\Lambda$ - macierz wartości własnych o wymiarach $n \times n$, $\Psi$ - macierz wektorów własnych o wymiarach $n \times n$, przy spełnieniu warunków ortogonalności

$$
\begin{aligned}
& \Psi^{T} \mathbf{K} \Psi=\Lambda \\
& \Psi^{T} \mathbf{M} \Psi=\mathbf{I}
\end{aligned}
$$

gdzie: I jest macierzą jednostkowa.

Po wprowadzeniu podziału współrzędnych uogólnionych $\mathbf{q}$ na współrzędne podstawowe $\mathbf{q}_{m}$ (master) oraz na współrzędne pomocnicze $\mathbf{q}_{s}$ (slave), równanie (1) przedstawiono w postaci:

$$
\left[\begin{array}{ll}
\mathbf{M}_{m m} & \mathbf{M}_{m s} \\
\mathbf{M}_{s m} & \mathbf{M}_{s s}
\end{array}\right]\left[\begin{array}{l}
\ddot{\mathbf{q}}_{m} \\
\ddot{\mathbf{q}}_{s}
\end{array}\right]+\left[\begin{array}{ll}
\mathbf{K}_{m m} & \mathbf{K}_{m s} \\
\mathbf{K}_{s m} & \mathbf{K}_{s s}
\end{array}\right]\left[\begin{array}{l}
\mathbf{q}_{m} \\
\mathbf{q}_{s}
\end{array}\right]=\left[\begin{array}{c}
\mathbf{B}_{m} \\
\mathbf{0}
\end{array}\right] \mathbf{f}_{(6)}
$$

Odpowiadające wyrażeniu (6) równanie uogólnionego zagadnienia własnego zapisano wzorem:

$$
\left(\left[\begin{array}{ll}
\mathbf{K}_{m m} & \mathbf{K}_{m s} \\
\mathbf{K}_{s m} & \mathbf{K}_{s s}
\end{array}\right]-\lambda\left[\begin{array}{ll}
\mathbf{M}_{m m} & \mathbf{M}_{m s} \\
\mathbf{M}_{s m} & \mathbf{M}_{s s}
\end{array}\right]\right)\left[\begin{array}{l}
\boldsymbol{\Psi}_{m} \\
\boldsymbol{\Psi}_{s}
\end{array}\right]=\mathbf{0}
$$

gdzie: $\lambda$ jest wartością własną układu.

$\mathrm{Z}$ zależności (7) uzyskano związek między wektorem $\psi s$ a wektorem $\psi_{m}$ :

$$
\boldsymbol{\psi}_{s}=-\left(\mathbf{K}_{s s}-\lambda \mathbf{M}_{s s}\right)^{-1}\left(\mathbf{K}_{m s}^{T}-\lambda \mathbf{M}_{m s}^{T}\right) \boldsymbol{\psi}_{m}=\mathbf{t} \boldsymbol{\psi}_{m}
$$

gdzie: $\mathbf{t}$ jest macierzą transformacji pomiędzy $\psi_{\mathrm{m}}$ oraz $\Psi s$.

Związek między wektorem $\psi$ o wymiarach $n \times 1$, reprezentującym postać drgań własnych układu, a wektorem $\psi m$ o wymiarach $m \times 1$ odpowiadającym kierunkom współrzędnych podstawowych $\mathbf{q}_{m}$ przedstawiono w postaci:

$$
\boldsymbol{\psi}=\left[\begin{array}{c}
\boldsymbol{\psi}_{m} \\
\boldsymbol{\psi}_{s}
\end{array}\right]=\left[\begin{array}{c}
\mathbf{I}_{m} \\
\mathbf{t}
\end{array}\right] \boldsymbol{\Psi}_{m}=\mathbf{T} \boldsymbol{\psi}_{m}
$$

gdzie: $\mathbf{T}$ jest macierzą transformacji pomiędzy $\psi$ oraz $\psi m$, a $\mathbf{I}_{m}$ jest macierzą jednostkową rzędu $m$.

Podstawiając równanie (9) do równania (3), a następnie mnożąc lewostronnie przez $\mathbf{T}^{T}$ uzyskano równanie opisujące uogólniony problem własny zredukowanego układu w postaci:

$$
\left(\mathbf{K}_{R}-\lambda \mathbf{M}_{R}\right) \boldsymbol{\psi}_{m}=\mathbf{0}
$$

gdzie: macierze sztywności $\mathbf{K}_{R}$ i bezwładności $\mathbf{M}_{R}$ układu po redukcji przedstawiono zależnościami:

$$
\begin{aligned}
\mathbf{K}_{R} & =\mathbf{T}^{T} \mathbf{K T} \\
\mathbf{M}_{R} & =\mathbf{T}^{T} \mathbf{M T}
\end{aligned}
$$

Rozwiązanie uogólnionego zagadnienia własnego dla zredukowanego układu (10) wymaga znajomości macierzy transformacji $\mathbf{t}$ zapisanej wzorem

$$
\mathbf{t}=-\left(\mathbf{K}_{s s}-\lambda \mathbf{M}_{s s}\right)^{-1}\left(\mathbf{K}_{m s}^{T}-\lambda \mathbf{M}_{m s}^{T}\right)
$$

W celu zbadania wpływu redukcji na działanie układu konieczne jest określenie zależności między wymuszeniem f f, a odpowiedzią $\mathbf{y}$ - równania (1) oraz (2). Po przeprowadzeniu transformacji Laplace'a oraz przyjęciu zerowych warunków początkowych $\dot{\mathbf{q}}(0)=\mathbf{q}(0)=\mathbf{0}$ uzyskano związek między transformatami wektora wyjścia i wektora wejścia w postaci:

$$
\mathbf{y}(s)=\mathbf{H}(s) \mathbf{f}(s)
$$

Transmitancję operatorową $\mathbf{H}(s)$ wyznaczono jako:

$$
\mathbf{H}(s)=\mathbf{D}\left(\mathbf{K}+s^{2} \mathbf{M}\right)^{-1} \mathbf{B}=\mathbf{D G}(s) \mathbf{B}
$$

gdzie: $\mathbf{G}(s)$ jest podatnością dynamiczną układu.

Transmitancja wyrażona za pomocą zależności (15) jest wymierną macierza, której elementy $h_{i j}(s)$ są przyczynowymi funkcjami wymiernymi

$$
h_{i j}(s)=\frac{a_{i j}(s)}{b_{i j}(s)}, \quad i=1, \ldots, p, \quad j=1, \ldots, r
$$

gdzie:

$a_{i j}(s)$ - licznik w postaci wielomianu zmiennej operatorowej,

$b_{i j}(s)$ - mianownik w postaci wielomianu zmiennej operatorowej.

W badaniach przyjęto, że w układzie występuje jedno wejście $\mathrm{w}$ postaci siły przyłożonej na kierunku wybranej współrzędnej uogólnionej oraz jedno wyjście w postaci przemieszczenia mierzonego na kierunku wybranej współrzędnej uogólnionej.

Przy tych założeniach zera transmitancji są równoważne pierwiastkom wielomianów występujących w licznikach odpowiednich skalarnych funkcji $h_{i j}(s)$ macierzy $\mathbf{H}(s)$, a bieguny są pierwiastkami wielomianów występujących w mianownikach tych funkcji.

\section{Badania numeryczne oceny jakości wybranych metod redukcji modelu}

Do badań przyjęto dyskretny model układu przedstawiony na rysunku 1 .

Model opisano dziesięciowymiarowym wektorem współrzędnych uogólnionych q.

$$
\mathbf{q}(t)=\left[\begin{array}{llll}
q_{1}(t) & q_{2}(t) & \ldots & q_{10}(t)
\end{array}\right]^{T}
$$

Macierz mas M modelu ma postać:

$$
\mathbf{M}=\operatorname{diag}\left(\left[\begin{array}{llll}
m_{1} & m_{2} & \ldots & m_{10}
\end{array}\right]\right)
$$

gdzie diag oznacza macierz diagonalną.

Macierz sztywności K przedstawiono wzorem:

$$
\mathbf{K}=\left[\begin{array}{cccccccccc}
K_{1} & -k_{1} & -k_{11} & 0 & 0 & 0 & 0 & 0 & 0 & 0 \\
-k_{1} & K_{2} & -k_{2} & -k_{12} & 0 & 0 & 0 & 0 & 0 & 0 \\
-k_{11} & -k_{2} & K_{3} & -k_{3} & -k_{13} & 0 & 0 & 0 & 0 & 0 \\
0 & -k_{12} & -k_{3} & K_{4} & -k_{4} & -k_{14} & 0 & 0 & 0 & 0 \\
0 & 0 & -k_{13} & -k_{4} & K_{5} & -k_{5} & -k_{15} & 0 & 0 & 0 \\
0 & 0 & 0 & -k_{14} & -k_{5} & K_{6} & -k_{6} & -k_{16} & 0 & 0 \\
0 & 0 & 0 & 0 & -k_{15} & -k_{6} & K_{7} & -k_{7} & -k_{17} & 0 \\
0 & 0 & 0 & 0 & 0 & -k_{16} & -k_{7} & K_{8} & -k_{8} & -k_{18} \\
0 & 0 & 0 & 0 & 0 & 0 & -k_{17} & -k_{8} & K_{9} & -k_{9} \\
0 & 0 & 0 & 0 & 0 & 0 & 0 & -k_{18} & -k_{9} & K_{10}
\end{array}\right]
$$




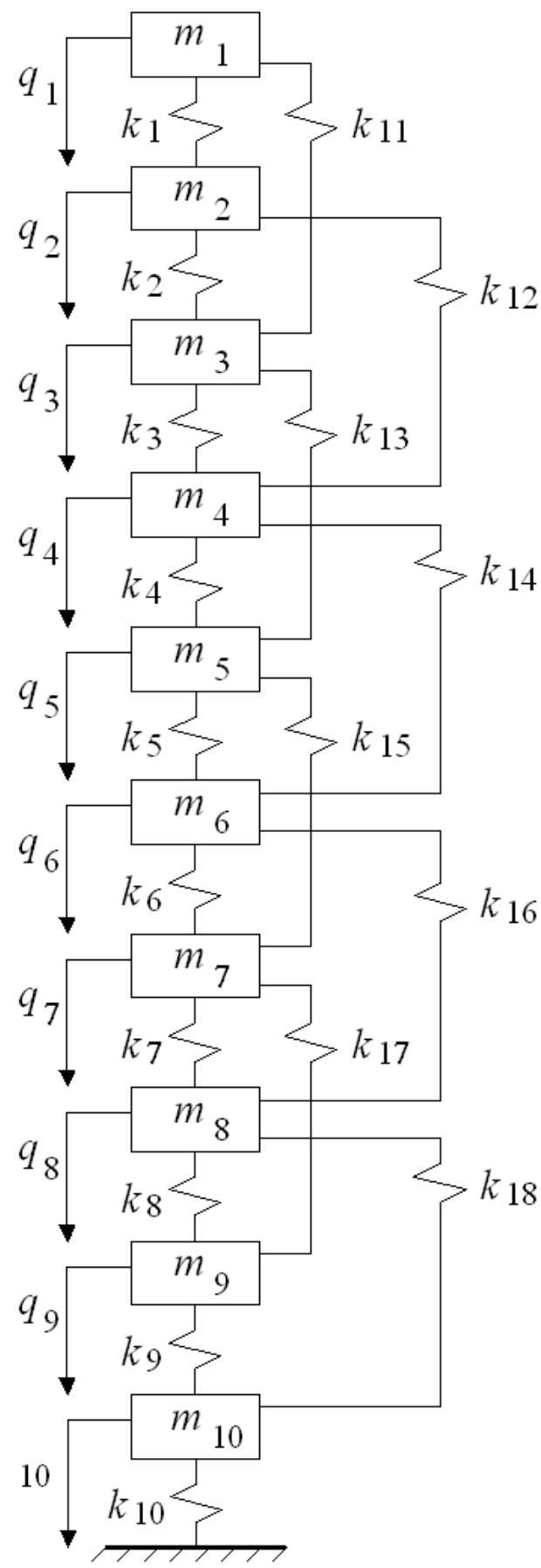

Rys. 1. Model układu przyjęty do badań

gdzie:

$K_{1}=k_{1}+k_{11}$

$K_{2}=k_{1}+k_{2}+k_{12}$

$K_{3}=k_{2}+k_{3}+k_{11}+k_{13}$,

$K_{4}=k_{3}+k_{4}+k_{12}+k_{14}$,

$K_{5}=k_{4}+k_{5}+k_{13}+k_{15}$,

$K_{6}=k_{5}+k_{6}+k_{14}+k_{16}$,

$K_{7}=k_{6}+k_{7}+k_{15}+k_{17}$,

$K_{8}=k_{7}+k_{8}+k_{16}+k_{18}$,

$K_{9}=k_{8}+k_{9}+k_{17}$

$K_{10}=k_{9}+k_{10}+k_{18}$
Po przeprowadzeniu wstępnych obliczeń numerycznych, przyjęto następujące wartości stałych charakterystyk masowych $[\mathrm{kg}]$ i sztywnościowych $10^{5}[\mathrm{~N} / \mathrm{m}]$ modelu:

$m_{1}=10, m_{2}=30, m_{3}=60, m_{4}=30, m_{5}=40, m_{6}=30, m_{7}=20, m_{8}=$ $30, m_{9}=10, m_{10}=20$,

$k_{1}=5, k_{2}=2, k_{3}=4, k_{4}=3, k_{5}=5, k_{6}=3, k_{7}=4, k_{8}=6, k_{9}=5, k_{10}=7$,

$k_{11}=k_{12}=k_{13}=k_{14}=k_{15}=k_{16}=k_{17}=k_{18}=3$.

Do badań przyjęto dwa warianty modelu, oznaczone odpowiednio $\boldsymbol{A}$ oraz $\boldsymbol{B}$. W wariancie $\boldsymbol{A}$ przyjęto wektor współrzędnych uogólnionych jak w równaniu (17). W wariancie $\boldsymbol{B}$ przyjęto wektor współrzędnych uogólnionych, których kolejność została ustalona według rosnącej wartości ilorazów wartości diagonalnych elementów macierzy sztywności do wartości diagonalnych elementów macierzy mas. Wektor współrzędnych uogólnionych dla modelu $\boldsymbol{A}$ ma postać:

${ }^{A} \mathbf{q}(t)=\left[\begin{array}{llllllllll}q_{1}(t) & q_{2}(t) & q_{3}(t) & q_{4}(t) & q_{5}(t) & q_{6}(t) & q_{7}(t) & q_{8}(t) & q_{9}(t) & q_{10}(t)\end{array}\right]^{T}$

a wektor współrzędnych uogólnionych dla modelu $\boldsymbol{B}$ ma postać:

$$
{ }^{B} \mathbf{q}(t)=\left[\begin{array}{llllllllll}
q_{3}(t) & q_{2}(t) & q_{5}(t) & q_{4}(t) & q_{6}(t) & q_{8}(t) & q_{7}(t) & q_{10}(t) & q_{1}(t) & q_{9}(t)
\end{array}\right]^{T}
$$

Po rozwiązaniu [9] uogólnionego zagadnienia własnego (3), dla modelu reprezentowanego macierzami ${ }^{A} \mathbf{M}$ oraz ${ }^{A} \mathbf{K}$, uzyskano wartości własne ${ }^{A} \Lambda$ :

$\boldsymbol{A}_{\boldsymbol{\Lambda}}=\operatorname{diag}\left(\left[\begin{array}{llllllllll}29,1 & 101,6 & 161,0 & 175,0 & 222,5 & 241,3 & 270,0 & 287,5 & 308,9 & 406,2])\end{array}\right.\right.$ oraz macierz wektorów własnych ${ }^{A} \Psi$ :

$A_{\boldsymbol{\Psi}} \boldsymbol{\Psi}=\left[\begin{array}{cccccccccc}-1,00 & -0,79 & 0,72 & -0,19 & 0,38 & -0,20 & -0,08 & -0,01 & -1,00 & 0,01 \\ -0,99 & -0,78 & 1,00 & -0,79 & 0,20 & -0,01 & -0,01 & 0,01 & 0,27 & -0,01 \\ -0,97 & -0,54 & -0,36 & 1,00 & 0,04 & -0,11 & -0,01 & -0,01 & 0,06 & 0,01 \\ -0,92 & -0,11 & -0,22 & -0,54 & -1,00 & 0,45 & 0,17 & -0,02 & -0,07 & 001 \\ -0,84 & 0,43 & -0,66 & -0,66 & 0,55 & 0,48 & -0,09 & 0,17 & -0,01 & -0,01 \\ -0,77 & 0,69 & -0,24 & -0,56 & -0,20 & -1,00 & -0,41 & -0,09 & 0,01 & -0,02 \\ -0,66 & 0,92 & 0,19 & 0,11 & 0,21 & -0,18 & 1,00 & -0,95 & -0,01 & 0,12 \\ -0,54 & 1,00 & 0,61 & 0,63 & -0,08 & 0,07 & 0,06 & 1,00 & -0,01 & 0,14 \\ -0,47 & 0,89 & 0,59 & 0,64 & -0,02 & 0,32 & -0,11 & -0,30 & -0,01 & -1,00 \\ -0,27 & 0,57 & 0,49 & 0,57 & -0,07 & 0,55 & -0,83 & -0,97 & 0,01 & 0,25\end{array}\right]$

W celu wyznaczenia zer transmitancji modelu (15) przyjęto wektor

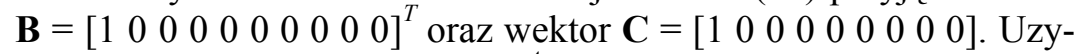
skano zera transmitancji modelu ${ }^{A} \mathrm{Z}$ :

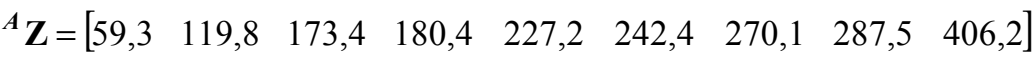

Po rozwiązaniu uogólnionego zagadnienia własnego (3), dla modelu reprezentowanego macierzami ${ }^{B} \mathbf{M}$ oraz ${ }^{B} \mathbf{K}$, uzyskano wartości własne ${ }^{B} \Lambda$ :

${ }^{\boldsymbol{B}} \boldsymbol{\Lambda}=\operatorname{diag}([29,1 \quad 101,6 \quad 161,0 \quad 175,0 \quad 222,5 \quad 241,3 \quad 270,0 \quad 287,5 \quad 308,9 \quad 406,2])={ }^{A} \boldsymbol{\Lambda}$ oraz macierz wektorów własnych ${ }^{\boldsymbol{B}} \Psi$ :

${ }^{\boldsymbol{B}} \boldsymbol{\Psi}=\left[\begin{array}{cccccccccc}-0,47 & 0,89 & 0,59 & -0,64 & 0,02 & 0,32 & -0,11 & -0,30 & 0,01 & 1,00 \\ -1,00 & -0,79 & 0,72 & 0,19 & -0,38 & -0,20 & -0,08 & -0,01 & 1,00 & -0,01 \\ -0,27 & 0,57 & 0,49 & -0,57 & 0,07 & 0,55 & -0,83 & -0,97 & -0,01 & -0,25 \\ -0,66 & 0,92 & 0,19 & -0,11 & -0,21 & -0,18 & 1,00 & -0,95 & 0,01 & -0,12 \\ -0,54 & 1,00 & 0,61 & -0,63 & 0,08 & 0,07 & 0,06 & 1,00 & 0,01 & -0,14 \\ -0,77 & 0,69 & -0,24 & 0,56 & 0,20 & -1,00 & -0,41 & -0,09 & -0,01 & 0,02 \\ -0,92 & -0,11 & -0,22 & 0,54 & 1,00 & 0,45 & 0,17 & -0,02 & 0,07 & -0,01 \\ -0,84 & 0,43 & -0,66 & 0,66 & -0,55 & 0,48 & -0,09 & 0,17 & 0,01 & 0,01 \\ -0,99 & -0,78 & 1,00 & 0,79 & -0,20 & -0,02 & -0,01 & 0,01 & -0,27 & 0,01 \\ -0,97 & -0,54 & -0,36 & -1,00 & -0,04 & -0,11 & -0,01 & -0,01 & -0,06 & -0,01\end{array}\right]$ 
W celu wyznaczenia zer transmitancji modelu (15) przyjęto wektor $\mathbf{B}=\left[\begin{array}{lllllllll}1 & 0 & 0 & 0 & 0 & 0 & 0 & 0 & 0\end{array}\right]^{T}$ oraz wektor $\mathbf{C}=\left[\begin{array}{lllllllll}1 & 0 & 0 & 0 & 0 & 0 & 0 & 0 & 0\end{array}\right]$. Uzyskano zera transmitancji modelu ${ }^{\boldsymbol{B}} \mathrm{Z}$ :

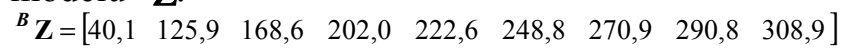

Dla każdego z modeli, analizie numerycznej poddano trzy warianty zredukowanych wektorów uogólnionych (20) i (21), przyjmując odpowiednio osiem pierwszych ${ }^{A} \mathbf{q}_{8} \mathrm{i}^{B}{ }^{B} \mathbf{q}_{8}$, sześć pierwszych ${ }^{A} \mathbf{q}_{6} \mathrm{i}^{B} \mathbf{q}_{6}$ oraz cztery pierwsze ${ }^{A} \mathbf{q}_{4}$ i ${ }^{B} \mathbf{q}_{4}$ współrzędne uogólnione.

Analize numeryczną w zakresie wyznaczenia macierzy redukcji, zredukowanych macierzy sztywności i bezwładności modelu przeprowadzono $\mathrm{z}$ zastosowaniem czterech metod [3,4,7 i 8].

\section{METODA (metoda Guyan'a)}

$\mathrm{W}$ metodzie [3] nie uwzględniono w (13) wyrażeń związanych $\mathrm{z}$ wartościami własnymi. Macierz transformacji $\mathbf{t}_{I}$ ma postać:

$$
\mathbf{t}_{I}=-\mathbf{K}_{s s}^{-1} \mathbf{K}_{m s}^{T}=\mathbf{t}_{G}
$$

Zredukowaną macierz sztywności $\mathbf{K}_{I}=\mathbf{K}_{G}$ zapisano w postaci:

$$
\mathbf{K}_{I}=\mathbf{K}_{m m}-\mathbf{K}_{m s} \mathbf{K}_{s s}^{-1} \mathbf{K}_{m s}^{T}
$$

a zredukowaną macierz bezwładności $\mathbf{M}_{I}=\mathbf{M}_{G} \mathrm{~W}$ postaci:

Częstotliwości drgań własnych [rad/s] modelu podstawowego oraz wariantów zredukowanych modeli ${ }^{A} \mathbf{q}_{8},{ }_{4}^{A} \mathbf{q}_{6},{ }^{A} \mathbf{q}_{4},{ }^{B} \mathbf{q}_{8},{ }^{B} \mathbf{q}_{6}$ oraz $^{B} \mathbf{q}_{4}$ przy za-

\begin{tabular}{|c|c|c|c|c|c|c|c|}
\hline \multicolumn{7}{|c|}{ stosowaniu $I$ metody } & \multirow{2}{*}{$\frac{\text { Tabela 1 }}{{ }^{B} \lambda_{I 4 i}}$} \\
\hline$i$ & $\lambda_{i}$ & ${ }^{A} \lambda_{I 8 i}$ & ${ }^{B} \lambda_{I 8 i}$ & ${ }^{A} \lambda_{I 6 i}$ & ${ }^{B} \lambda_{I 6 i}$ & ${ }^{A} \lambda_{I 4 i}$ & \\
\hline 1 & 29,19 & 29,19 & 29,48 & 29,26 & 30,07 & 29,64 & 30,66 \\
\hline 2 & 101,64 & 102,43 & 108,36 & 112,52 & 111,72 & - & 115,93 \\
\hline 3 & 161,05 & 163,03 & - & 168,50 & - & 156,20 & - \\
\hline 4 & 175,04 & 177,52 & 171,78 & - & 188,45 & 177,01 & - \\
\hline 5 & 222,55 & 222,62 & 226,39 & 222,42 & - & - & - \\
\hline 6 & 241,37 & 245,82 & 239,38 & 224,44 & - & - & 234,57 \\
\hline 7 & 270,03 & 278,79 & 270,04 & - & 266,64 & - & - \\
\hline 8 & 287,53 & - & 287,41 & - & 283,44 & - & - \\
\hline 9 & 308,98 & 308,98 & - & 308,9 & - & 308,69 & - \\
\hline 10 & 406,26 & - & 406,26 & - & 406,04 & - & 368,54 \\
\hline
\end{tabular}
stosowaniu $I$ metody

Miara podobieństwa pierwszej postaci drgań wlasnych mode-

lu podstawowego do pierwszej postaci drgań wlasnych wa-

riantów zredukowanych modeli ${ }^{A} \mathbf{q}_{8},{ }^{A} \mathbf{q}_{6},{ }^{A} \mathbf{q}_{4},{ }^{B} \mathbf{q}_{8},{ }^{B} \mathbf{q}_{6}$ oraz ${ }^{B} \mathbf{q}_{4}$

\begin{tabular}{|c|c|c|c|c|c|c|}
\hline$i$ & $\frac{{ }^{A} \psi_{1 i}}{{ }^{A} \psi_{I 81 i}}$ & $\frac{{ }^{A} \psi_{1 i}}{{ }^{A} \psi_{I 61 i}}$ & $\frac{{ }^{A} \psi_{1 i}}{{ }^{A} \psi_{I 41 i}}$ & $\frac{{ }^{B} \psi_{1 i}}{{ }^{B} \psi_{I 81 i}}$ & $\frac{{ }^{B} \psi_{1 i}}{{ }^{B} \psi_{I 61 i}}$ & $\frac{{ }^{\boldsymbol{B}} \psi_{1 i}}{{ }^{\boldsymbol{B}} \psi_{I 41 i}}$ \\
\hline 1 & 0,999 & 0,994 & 0,967 & 0,978 & 0,937 & 0,902 \\
\hline 2 & 0,999 & 0,994 & 0,967 & 0,981 & 0,943 & 0,906 \\
\hline 3 & 0,999 & 0,994 & 0,968 & 0,977 & 0,936 & 0,901 \\
\hline 4 & 0,999 & 0,994 & 0,969 & 0,978 & 0,938 & 0,903 \\
\hline 5 & 0,999 & 0,995 & 1,043 & 0,978 & 0,937 & 0,944 \\
\hline 6 & 0,999 & 0,995 & 1,060 & 0,979 & 0,940 & 1,007 \\
\hline 7 & 0,999 & 1,031 & 1,091 & 0,980 & 1,024 & 1,034 \\
\hline 8 & 0,999 & 1,048 & 1,111 & 0,979 & 1,007 & 1,025 \\
\hline 9 & 1,009 & 1,052 & 1,115 & 1,016 & 1,009 & 0,989 \\
\hline 10 & 1,017 & 1,062 & 1,126 & 1,030 & 1,039 & 1,031 \\
\hline
\end{tabular}
przy zastosowaniu $I$ metody
$\mathbf{M}_{I}=\mathbf{M}_{m m}-\mathbf{M}_{m s} \mathbf{K}_{s s}^{-1} \mathbf{K}_{m s}^{T}-\mathbf{K}_{m s} \mathbf{K}_{s s}^{-1} \mathbf{M}_{m s}^{T}+\mathbf{K}_{m s} \mathbf{K}_{s s}^{-1} \mathbf{M}_{s s} \mathbf{K}_{s s}^{-1} \mathbf{K}_{m s}^{T}$

Po podstawieniu zredukowanych macierzy bezwładności $\mathbf{M}_{I}$ oraz sztywności $\mathbf{K}_{I}$ do równania na uogólniony problem własny (10) wyznaczono wartości własne i wektory własne. Częstotliwości odpowiadające wyznaczonym wartościom własnym zebrano $\mathrm{w}$ tabeli 1.

W celu porównania postaci drgań własnych (odpowiadającym wektorom własnym) wyznaczonych dla modelu podstawowego (3) oraz dla modelu zredukowanego (9) wprowadzono miare w postaci ilorazu kolejnych współrzędnych wektorów własnych. Dla wektorów podobnych wartości tych ilorazów są sobie równe. $\mathrm{W}$ tabeli 2 przedstawiono miary podobieństwa postaci drgań własnych odpowiadających pierwszej częstotliwości drgań własnych (miar dla kolejnych postaci drgań własnych nie przedstawiono, ponieważ nie wykazywały podobieństwa).

Macierz transformacji ${ }^{A} \mathbf{T}_{14}$ uzyskana przy zastosowaniu $I$ metody dla wariantu redukcji do wektora współrzędnych uogólnionych ${ }^{A} \mathbf{q}_{4}$ oraz macierz transforma${ }^{\text {cji }}{ }^{B} \mathbf{T}_{I 4}$ uzyskana przy zastosowaniu $I$ metody dla wariantu redukcji do wektora współrzędnych uogólnionych ${ }^{B} \mathbf{q}_{4}$ mają postać: 
Zera transmitancji modelu podstawowego oraz wariantów zredukowanych modeli ${ }^{A} \mathbf{q}_{8},{ }^{A} \mathbf{q}_{6},{ }^{A} \mathbf{q}_{4},{ }^{B} \mathbf{q}_{8},{ }^{B} \mathbf{q}_{6} \operatorname{oraz}^{B} \mathbf{q}_{4}$ przy zastosowaniu $I$ metody

Tabela 3

\begin{tabular}{|c|c|c|c|c|c|c|c|}
\hline$j$ & \multicolumn{1}{c|}{$\zeta_{j}$} & ${ }^{A} \zeta_{I 8 j}$ & ${ }^{B} \zeta_{I 8 j}$ & ${ }^{A} \zeta_{I 6 j}$ & ${ }^{B} \zeta_{I 6 j}$ & ${ }^{A} \zeta_{I 4 j}$ & ${ }^{B} \zeta_{I 4 j}$ \\
\hline 1 & 59,30 & 59,37 & 41,12 & 60,57 & 42,94 & 66,43 & 44,54 \\
\hline 2 & 119,87 & 121,14 & 136,27 & 134,54 & 140,69 & - & - \\
\hline 3 & 173,47 & 177,34 & - & - & - & 176,70 & 162,47 \\
\hline 4 & 180,46 & 180,66 & 201,30 & 180,35 & - & 190,44 & - \\
\hline 5 & 227,25 & 227,26 & 226,70 & 224,42 & 222,18 & - & - \\
\hline 6 & 242,42 & 246,88 & 247,29 & 229,24 & - & - & - \\
\hline 7 & 270,14 & 278,81 & 270,93 & - & 267,25 & - & 265,47 \\
\hline 8 & 287,53 & - & 290,72 & - & 287,72 & - & - \\
\hline 9 & 406,26 & - & - & - & - & - & - \\
\hline
\end{tabular}

\section{METODA}

$\mathrm{W}$ metodzie [3] macierz transformacji utworzono przez zastapienie członów związanych $\mathrm{z}$ bezwładnościa, wielkościami o charakterze pseudo-statycznego obciążenia. Przekształcając równanie w wyrażeniu (6), przy przyjęciu wymuszenia o charakterze harmonicznym o częstotliwości $\omega$ uzyskano związek:

$\left[\mathbf{K}_{s s}-\omega^{2} \mathbf{M}_{s s}\right] \boldsymbol{\psi}_{s}=-\left[\mathbf{K}_{s m}-\omega^{2} \mathbf{M}_{s m}\right] \boldsymbol{\psi}_{m}$

Po przekształceniu (20) uzyskano zależność między wektorem $\psi$ s, a wektorem $\psi m$

$\boldsymbol{\psi}_{s}=-\left[\mathbf{K}_{s s}-\omega^{2} \mathbf{M}_{s s}\right]^{-1}\left[\mathbf{K}_{s m}-\omega^{2} \mathbf{M}_{s m}\right] \boldsymbol{\psi}_{m}(26)$

W wyniku zastosowania rozkładu macierzy podatności w szereg dwumianowy otrzymano przekształcona zależność:

$\boldsymbol{\psi}_{s}=-\mathbf{K}_{s s}^{-1}\left[\mathbf{I}-\omega^{2} \mathbf{M}_{s s} \mathbf{K}_{s s}^{-1}\right]^{-1}\left[\mathbf{K}_{s m}-\omega^{2} \mathbf{M}_{s m}\right] \boldsymbol{\psi}_{m}(27)$ a po wprowadzeniu błędu względem $\omega$ związek:

$\boldsymbol{\psi}_{s}=-\mathbf{K}_{s s}^{-1}\left[\mathbf{K}_{s m}+\omega^{2}\left(\mathbf{M}_{s s} \mathbf{K}_{s s}^{-1} \mathbf{K}_{s m}-\mathbf{M}_{s m}\right)+\mathbf{o}\left(\omega^{4}\right)\right] \boldsymbol{\psi}_{m}$

gdzie: $\mathbf{o}\left(\omega^{4}\right)$ oznacza błąd czwartego rzędu względem $\omega$. Zakładając, że przy przyjęciu wyrazów pierwszego rzędu ze względu na $\omega^{2}$ spełnione są równania:

$$
\begin{aligned}
& \omega^{2} \mathbf{M}_{G} \boldsymbol{\psi}_{m}=\mathbf{K}_{G} \boldsymbol{\psi}_{m} \\
& \omega^{2} \boldsymbol{\psi}_{m}=\mathbf{M}_{G}^{-1} \mathbf{K}_{G} \boldsymbol{\Psi}_{m}
\end{aligned}
$$

uzyskano macierz transformacji $\mathbf{t}_{I I}$ :

$$
\mathbf{t}_{I I}=-\mathbf{K}_{s s}^{-1} \mathbf{K}_{s m}+\mathbf{K}_{s s}^{-1}\left(\mathbf{M}_{s m}-\mathbf{M}_{s s} \mathbf{K}_{s s}^{-1} \mathbf{K}_{s m}\right) \mathbf{M}_{G}^{-1} \mathbf{K}_{G}
$$

Macierz sztywności $\mathbf{K}_{I I}$ i bezwładności $\mathbf{M}_{I I}$ zredukowanego układu wyznaczono według związków:

$$
\begin{aligned}
\mathbf{K}_{I I} & =\mathbf{T}_{I I}^{T} \mathbf{K} \mathbf{T}_{I I} \\
\mathbf{M}_{I I} & =\mathbf{T}_{I I}^{T} \mathbf{M} \mathbf{T}_{I I}
\end{aligned}
$$

gdzie:

$$
\mathbf{T}_{I I}=\left[\begin{array}{l}
\mathbf{I}_{m} \\
\mathbf{t}_{I I}
\end{array}\right]
$$

Po podstawieniu zredukowanych macierzy bezwładności $\mathbf{M}_{I I}$ oraz sztywności $\mathbf{K}_{I I}$ do równania na uogólniony problem własny (10) wyznaczono wartości własne i wektory własne. Częstotliwości odpowiadające wyznaczonym wartościom własnym zebrano w tabeli 4.

Częstotliwości drgań własnych [rad/s] modelu podstawowego oraz wariantów zredukowanych modeli ${ }^{A} \mathbf{q}_{8},{ }^{A} \mathbf{q}_{6},{ }^{A} \mathbf{q}_{4},{ }^{B} \mathbf{q}_{8},{ }^{B} \mathbf{q}_{6}$ oraz ${ }^{B} \mathbf{q}_{4}$ przy zastosowaniu II metody

Tabela 4

\begin{tabular}{|c|r|r|r|r|r|r|c|}
\hline$i$ & \multicolumn{1}{|c|}{$\lambda_{i}$} & ${ }^{A} \lambda_{I I 8 i}$ & ${ }^{B} \lambda_{I I 8 i}$ & ${ }^{A} \lambda_{I I 6 i}$ & ${ }^{B} \lambda_{I I 6 i}$ & ${ }^{A} \lambda_{I I 4 i}$ & ${ }^{B} \lambda_{I L 4 i}$ \\
\hline 1 & 29,19 & 29,19 & 29,19 & 29,19 & 29,19 & 29,19 & 29,19 \\
\hline 2 & 101,64 & 101,65 & 101,82 & 101,89 & 102,75 & 110,82 & 101,99 \\
\hline 3 & 161,05 & 161,31 & 164,18 & - & 166,41 & - & - \\
\hline 4 & 175,04 & 175,38 & - & 170,46 & 197,39 & 169,22 & 186,08 \\
\hline 5 & 222,55 & 222,58 & 223,55 & - & 222,91 & - & - \\
\hline 6 & 241,37 & 243,91 & 229,93 & - & - & - & - \\
\hline 7 & 270,03 & 277,51 & 270,01 & 262,56 & - & - & - \\
\hline 8 & 287,53 & - & 286,82 & 278,89 & - & - & - \\
\hline 9 & 308,98 & 308,98 & - & - & 308,89 & 307,37 & 311,97 \\
\hline 10 & 406,26 & - & 406,25 & 404,27 & - & - & - \\
\hline
\end{tabular}


Miara podobieństwa pierwszej postaci drgań własnych modelu podstawowego do pierwszej postaci drgań własnych wariantów zredukowanych modeli ${ }^{A} \mathbf{q}_{8},{ }^{A} \mathbf{q}_{6}$, ${ }^{A} \mathbf{q}_{4},{ }^{B} \mathbf{q}_{8},{ }^{B} \mathbf{q}_{6}$ oraz ${ }^{B} \mathbf{q}_{4}$ przy zastosowaniu $I I$ metody

\begin{tabular}{|c|r|r|r|r|r|r|}
\hline$i$ & ${ }^{A} \psi_{1 i}$ & ${ }^{A} \psi_{1 i}$ & ${ }^{A} \psi_{1 i}$ & ${ }^{B} \psi_{1 i}$ & ${ }^{B} \psi_{1 i}$ & ${ }^{{ }^{B}} \psi_{1 i}$ \\
\hline 1 & ${ }^{A} \psi_{I I 81 i}$ & ${ }^{A} \psi_{I I 61 i}$ & ${ }^{A} \psi_{I I 41 i}$ & ${ }^{B} \psi_{I I 81 i}$ & ${ }^{B} \psi_{I I 61 i}$ & ${ }^{B} \psi_{I I 41 i}$ \\
\hline 2 & 1,000 & 1,000 & 0,999 & 1,000 & 1,000 & 0,999 \\
\hline 3 & 1,000 & 1,000 & 0,999 & 0,999 & 0,998 & 0,998 \\
\hline 4 & 1,000 & 1,000 & 0,999 & 1,000 & 1,000 & 0,999 \\
\hline 5 & 1,000 & 1,000 & 0,997 & 1,000 & 0,999 & 0,998 \\
\hline 6 & 1,000 & 0,999 & 1,000 & 1,000 & 1,000 & 0,999 \\
\hline 7 & 1,000 & 1,000 & 1,000 & 0,999 & 0,999 & 1,000 \\
\hline 8 & 1,000 & 1,000 & 1,003 & 0,999 & 1,000 & 1,000 \\
\hline 9 & 1,000 & 1,000 & 1,003 & 0,999 & 1,000 & 1,000 \\
\hline 10 & 1,000 & 1,000 & 1,004 & 1,000 & 0,999 & 0,999 \\
\hline
\end{tabular}

W celu porównania postaci drgań własnych (odpowiadającym wektorom własnym) wyznaczonych dla modelu podstawowego (3) oraz dla modelu zredukowanego (9) wprowadzono miare $\mathrm{W}$ postaci ilorazu kolejnych współrzędnych wektorów własnych. Dla wektorów podobnych wartości tych ilorazów są sobie równe. $\mathrm{W}$ tabeli 5 przedstawiono miary podobieństwa postaci drgań własnych odpowiadających pierwszej częstotliwości drgań własnych (miar dla kolejnych postaci drgań własnych nie przedstawiono, ponieważ nie wykazywały podobieństwa).

Macierz transformacji ${ }^{A} \mathbf{T}_{I I 4}$ uzyskana przy zastosowaniu II metody dla wariantu redukcji do wektora współrzędnych uogólnionych ${ }^{A} \mathbf{q}_{4}$ oraz macierz transformacji ${ }^{B} \mathbf{T}_{I I 4}$ uzyskana przy zastosowaniu $I I$ metody dla wariantu redukcji do wektora współrzędnych uogólnionych ${ }^{B} \mathbf{q}_{4}$ mają postać:

$$
{ }^{A} \mathbf{T}_{I I 4}=\left[\begin{array}{cccc}
1 & 0 & 0 & 0 \\
0 & 1 & 0 & 0 \\
0 & 0 & 1 & 0 \\
0 & 0 & 0 & 1 \\
-0,05 & -0,25 & 0,13 & 1,10 \\
-0,05 & -0,28 & -0,09 & 1,29 \\
-0,05 & -0,31 & -0,10 & 1,22 \\
-0,05 & -0,29 & -0,14 & 1,12 \\
-0,04 & -0,26 & -0,12 & 0,98 \\
-0,02 & -0,16 & -0,08 & 0,58
\end{array}\right]
$$

Zera transmitancji modelu podstawowego oraz wariantów zredukowanych modeli ${ }^{A} \mathbf{q}_{8},{ }^{A} \mathbf{q}_{6},{ }^{A} \mathbf{q}_{4}$, ${ }^{B} \mathrm{q}_{8},{ }^{B} \mathrm{q}_{6}$ oraz ${ }^{B} \mathrm{q}_{4}$ przy zastosowaniu $I I$ metody

\begin{tabular}{|c|c|c|c|c|c|c|c|}
\hline$j$ & $\zeta_{j}$ & ${ }^{A} \zeta_{I I 8 j}$ & ${ }^{B} \zeta_{I I 8 j}$ & ${ }^{A} \zeta_{I I 6 j}$ & ${ }^{B} \zeta_{I I 6 j}$ & ${ }^{A} \zeta_{I I 4 j}$ & ${ }^{B} \zeta_{I I 4 j}$ \\
\hline 1 & 40,19 & 59,30 & 40,19 & 59,32 & 40,19 & 59,49 & 41,99 \\
\hline 2 & 125,93 & 119,92 & 126,36 & 122,72 & 126,78 & 138,28 & 134,78 \\
\hline 3 & 168,67 & 174,07 & - & 180,28 & - & - & - \\
\hline 4 & 202,00 & 180,48 & 194,89 & 200,54 & 210,94 & 181,25 & - \\
\hline 5 & 222,60 & 227,25 & 223,58 & 227,75 & - & - & - \\
\hline 6 & 248,87 & 245,02 & 240,81 & - & - & - & - \\
\hline 7 & 270,93 & 277,54 & 270,92 & - & 262,80 & - & 269,94 \\
\hline 8 & 290,80 & - & 290,31 & - & 284,26 & - & - \\
\hline 9 & 308,98 & - & - & - & - & - & - \\
\hline
\end{tabular}

Po podstawieniu zredukowanych macierzy bezwładności $\mathbf{M}_{I I}$ oraz sztywności $\mathbf{K}_{I I}$ do równania (15) wyznaczono zera transmitancji badanych wariantów zredukowanych modeli, które zebrano w tabeli 6.

\section{METODA}

W metodzie [7] zamiast aproksymacji w postaci pominięcia $\mathrm{w}$ równaniu macierzy transformacji składników wyższego rzędu względem częstotliwości, wprowadzono iteracyjny sposób jej określania. Mnożąc wyrażenie (13) przez wyrażenie $\left(\mathbf{K}_{s s}-\lambda \mathbf{M}_{s s}\right)$ uzyskano po przekształceniach:

$$
\mathbf{t}=-\mathbf{K}_{s s}^{-1} \mathbf{K}_{m s}^{T}+\lambda \mathbf{K}_{s s}^{-1}\left(\mathbf{M}_{m s}^{T}+\mathbf{M}_{s s} \mathbf{t}\right)
$$

Równanie (35) świadczy o zasadności stosowania iteracyjnej formy znajdowania postaci macierzy transformacji t.

Równanie reprezentujące uogólnione zagadnienie własne dla modelu o $m$ wektorach własnych ma postać:

$$
\left[\begin{array}{ll}
\mathbf{K}_{m m} & \mathbf{K}_{m s} \\
\mathbf{K}_{s m} & \mathbf{K}_{s s}
\end{array}\right]\left[\begin{array}{l}
\boldsymbol{\Psi}_{m m} \\
\boldsymbol{\Psi}_{s m}
\end{array}\right]=\left[\begin{array}{ll}
\mathbf{M}_{m m} & \mathbf{M}_{m s} \\
\mathbf{M}_{s m} & \mathbf{M}_{s s}
\end{array}\right]\left[\begin{array}{l}
\boldsymbol{\Psi}_{m m} \\
\boldsymbol{\Psi}_{s m}
\end{array}\right] \boldsymbol{\Lambda}_{m m}
$$

Po przekształceniu drugiego równania $\mathrm{z}$ zależności (36) uzyskano związek między macierzami $\Psi_{m m}$ oraz $\Psi_{s m}$. 


$$
\boldsymbol{\Psi}_{s m}=\left[-\mathbf{K}_{s s}^{-1} \mathbf{K}_{m s}^{T}+\mathbf{K}_{s s}^{-1}\left(\mathbf{M}_{m s}^{T}+\mathbf{M}_{s s} \mathbf{t}\right) \boldsymbol{\Psi}_{m m} \boldsymbol{\Lambda}_{m m} \boldsymbol{\Psi}_{m m}^{-1}\right] \boldsymbol{\Psi}_{m m}
$$

Macierz transformacji $\mathbf{t}_{I I I}$ oznaczono zatem jako:

$$
\mathbf{t}_{I I I}=\mathbf{t}_{G}+\mathbf{t}_{d}
$$

gdzie:

$$
\mathbf{t}_{d}=\mathbf{K}_{s s}^{-1}\left(\mathbf{M}_{m s}^{T}+\mathbf{M}_{s s} \mathbf{t}\right) \boldsymbol{\Psi}_{m m} \boldsymbol{\Lambda}_{m m} \boldsymbol{\Psi}_{m m}^{-1}
$$

Oznaczając macierz transformacji T jako:

$$
\mathbf{T}=\left[\begin{array}{c}
\mathbf{I}_{m m} \\
\mathbf{t}_{G}+\mathbf{t}_{d}
\end{array}\right]
$$

wyznaczono zgodnie ze wzorami (11) oraz (12) macierz sztywności $\mathbf{K}_{R}$ oraz macierz bezwładności $\mathbf{M}_{R}$. Po podstawieniu wyznaczonych $\mathbf{K}_{R}$ oraz $\mathbf{M}_{R}$ do równania (10) na uogólnione zagadnienie własne i wykonaniu odpowiednich przekształceń uzyskano związek $\mathbf{K}_{G} \boldsymbol{\Psi}_{m m}=\left[\mathbf{M}_{G}+\left(\mathbf{M}_{m s}+\mathbf{t}_{G}^{T} \mathbf{M}_{s s}\right) \mathbf{t}_{d}\right] \boldsymbol{\Psi}_{m m} \boldsymbol{\Lambda}_{m m}=\mathbf{M}_{d} \boldsymbol{\Psi}_{m m} \boldsymbol{\Lambda}_{m m}$

Ze wzoru (41) uzyskano

$$
\boldsymbol{\Psi}_{m m} \Lambda_{m m} \boldsymbol{\Psi}_{m m}^{-1}=\mathbf{M}_{d}^{-1} \mathbf{K}_{G}
$$

Po wykorzystaniu związku (39) w równaniu (36) uzyskano ostateczną postać wzoru na macierz transformacji $\mathbf{t}_{d}$ :

$$
\mathbf{t}_{d}=\mathbf{K}_{s s}^{-1}\left(\mathbf{M}_{m s}^{T}+\mathbf{M}_{s s} \mathbf{t}\right) \mathbf{M}_{d}^{-1} \mathbf{K}_{G}
$$

Macierz transformacji $\mathbf{t}_{I I I}$ zapisano w postaci schematu iteracyjnego

$$
\mathbf{t}_{I I I}^{(k)}=\mathbf{t}_{G}+\mathbf{K}_{s s}^{-1}\left(\mathbf{M}_{m s}^{T}+\mathbf{M}_{s s} \mathbf{t}_{I I I}^{(k-1)}\right)\left[\mathbf{M}_{d}^{(k-1)}\right]^{-1} \mathbf{K}_{G}
$$

Macierz transformacji $\mathbf{T}_{I I I}^{(k)}$ ma postać:

$$
\mathbf{T}_{I I I}^{(k)}=\left[\begin{array}{l}
\mathbf{I}_{m m} \\
\mathbf{t}_{I I I}^{(k)}
\end{array}\right]
$$

Macierz $\mathbf{M}_{d}^{(k-1)}$ przedstawiono związkiem:

$$
\mathbf{M}_{d}^{(k-1)}=\mathbf{M}_{G}+\left(\mathbf{M}_{m s}+\mathbf{t}_{G}^{T} \mathbf{M}_{s s}\right) \mathbf{t}_{d}^{(k-1)}
$$

Jako warunek zakończenia procedury iteracyjnej przyjęto spełnienie nierówności:

$$
\left|\frac{\lambda_{j}^{(i+k)}-\lambda_{j}^{(i)}}{\lambda_{j}^{(i+k)}}\right|<\varepsilon_{j} \text { dla } j=1,2, \ldots, m
$$

gdzie $\varepsilon_{j}$ jest zadaną wartością determinującą dokładność wyników.

Po podstawieniu zredukowanych macierzy bezwładności ${ }^{A} \mathbf{M}_{I I I}$ oraz sztywności ${ }^{A} \mathbf{K}_{I I I}$ do równania na uogólniony problem własny (10) wyznaczono wartości własne i wektory własne. Częstotliwości odpowiadające wyznaczonym wartościom własnym

\begin{tabular}{|c|c|c|c|c|c|c|c|c|}
\hline$i$ & $\frac{{ }^{A} \psi_{1 i}}{{ }^{A} \psi_{I I I 81 i}}$ & $\frac{{ }^{A} \psi_{2 i}}{{ }^{A} \psi_{I I I 82 i}}$ & $\frac{{ }^{A} \psi_{3 i}}{{ }^{A} \psi_{I I I 83 i}}$ & $\frac{{ }^{A} \psi_{4 i}}{{ }^{A} \psi_{I I I 84 i}}$ & $\frac{{ }^{A} \psi_{5 i}}{{ }^{A} \psi_{I I I 85 i}}$ & $\frac{{ }^{A} \psi_{6 i}}{{ }^{A} \psi_{I I I 86 i}}$ & $\frac{{ }^{A} \psi_{7 i}}{{ }^{A} \psi_{I I I 87 i}}$ & $\frac{{ }^{A} \psi_{8 i}}{{ }^{A} \psi_{I I I 88 i}}$ \\
\hline 1 & 1.000 & 1.000 & 1.000 & 1.000 & 1.000 & 1.000 & 1.000 & 0.998 \\
\hline 2 & 1.000 & 1.000 & 1.000 & 1.000 & 1.000 & 1.000 & 1.000 & 0.999 \\
\hline 3 & 1.000 & 1.000 & 1.000 & 1.000 & 1.000 & 1.000 & 1.000 & 1.000 \\
\hline 4 & 1.000 & 1.000 & 1.000 & 1.000 & 1.000 & 1.000 & 1.000 & 1.000 \\
\hline 5 & 1.000 & 1.000 & 1.000 & 1.000 & 1.000 & 1.000 & 1.000 & 1.000 \\
\hline 6 & 1.000 & 1.000 & 1.000 & 1.000 & 1.000 & 1.000 & 1.000 & 1.000 \\
\hline 7 & 1.000 & 1.000 & 1.000 & 1.000 & 1.000 & 1.000 & 1.000 & 1.000 \\
\hline 8 & 1.000 & 1.000 & 1.000 & 1.000 & 1.000 & 1.000 & 1.000 & 1.000 \\
\hline 9 & 1.000 & 1.000 & 1.000 & 1.000 & 1.000 & 1.000 & 1.000 & 1.000 \\
\hline 10 & 1.000 & 1.000 & 1.000 & 1.000 & 1.000 & 1.000 & 1.000 & 1.000 \\
\hline
\end{tabular}
zebrano w tabeli 7 - indeks $(k)$ przy ${ }^{A} \lambda^{(k)}$ oznacza numer iteracji.

Częstotliwości drgań własnych [rad/s] modelu podstawowego oraz wariantów zredukowanych modeli ${ }^{A} \mathrm{q}_{8},{ }^{A} \mathrm{q}_{6}$ oraz ${ }^{A} \mathrm{q}_{4}$ przy zastosowaniu III metody

Tabela 7

\begin{tabular}{|c|c|c|c|c|c|c|c|c|r|r|}
\hline$i$ & \multicolumn{1}{c|}{$\lambda_{i}$} & ${ }^{\boldsymbol{A}} \lambda_{I I I 8 i}^{(1)}$ & ${ }^{\boldsymbol{A}} \lambda_{I I I 8 i}^{(2)}$ & ${ }^{\boldsymbol{A}} \lambda_{I I I 8 i}^{(k)}$ & ${ }^{\boldsymbol{A}} \lambda_{I I I 6 i}^{(1)}$ & ${ }^{\boldsymbol{A}} \lambda_{I I I 6 i}^{(2)}$ & ${ }^{\boldsymbol{A}} \lambda_{I I I 6 i}^{(k)}$ & ${ }^{\boldsymbol{A}} \lambda_{I I I 4 i}^{(1)}$ & ${ }^{\boldsymbol{A}} \lambda_{I I I 4 i}^{(2)}$ & ${ }^{\boldsymbol{A}} \lambda_{I I I 4 i}^{(k)}$ \\
\hline 1 & 29,19 & 29,19 & 29,19 & 29,19 & 29,26 & 29,19 & 29,19 & 29,64 & 29,21 & 29,19 \\
\hline 2 & 101,64 & 102,43 & 101,74 & 101,64 & 112,52 & 105,45 & 101,64 & - & 128,17 & 101,64 \\
\hline 3 & 161,05 & 163,03 & 161,78 & 161,05 & 168,50 & 167,53 & 161,05 & 156,20 & - & 161,05 \\
\hline 4 & 175,04 & 177,52 & 175,94 & 175,04 & - & - & 175,04 & 177,01 & 170,84 & 175,04 \\
\hline 5 & 222,55 & 222,62 & 222,59 & 222,55 & 222,42 & 210,32 & 222,55 & - & - & - \\
\hline 6 & 241,37 & 245,82 & 244,71 & 241,37 & 224,44 & 223,09 & 241,37 & - & - & - \\
\hline 7 & 270,03 & 278,79 & 278,13 & 270,03 & - & - & - & - & - & - \\
\hline 8 & 287,53 & - & - & 287,54 & - & - & - & - & - & - \\
\hline 9 & 308,98 & 308,98 & 308,98 & - & 308,96 & 308,93 & - & 308,69 & 308,29 & - \\
\hline 10 & 406,26 & - & - & - & - & - & - & - & - & - \\
\hline
\end{tabular}

Miara podobieństwa postaci drgań własnych modelu podstawowego do postaci drgań własnych zredukowanego modelu ${ }^{A} \mathrm{q}_{8}$ przy zastosowaniu III metody 
Miara podobieństwa postaci drgań własnych modelu podstawowego do postaci drgań własnych zredukowanego modelu ${ }^{A} q_{6}$ przy zastosowaniu $I I I$ metody

Tabela 9

\begin{tabular}{|c|c|c|c|c|c|c|}
\hline \multirow{2}{*}{$i$} & ${ }^{A} \psi_{1 i}$ & ${ }^{A} \psi_{2 i}$ & ${ }^{A} \psi_{3 i}$ & ${ }^{A} \psi_{4 i}$ & ${ }^{A} \psi_{5 i}$ & ${ }^{A} \psi_{6 i}$ \\
\hline & ${ }^{A} \psi_{I I I 61 i}$ & ${ }^{A} \psi_{I I I 62 i}$ & ${ }^{A} \psi_{I I I 63 i}$ & ${ }^{A} \psi_{I I I 64 i}$ & ${ }^{A} \psi_{I I I 65 i}$ & ${ }^{A} \psi_{I I I 66 i}$ \\
\hline 1 & 1,000 & 1,000 & 1,000 & 1,000 & 1,000 & 0.999 \\
\hline 2 & 1,000 & 1,000 & 1,000 & 1,000 & 1,000 & 0.999 \\
\hline 3 & 1,000 & 1,000 & 1,000 & 1,000 & 1,000 & 1,000 \\
\hline 4 & 1,000 & 1,000 & 1,000 & 1,000 & 1,000 & 0.999 \\
\hline 5 & 1,000 & 1,000 & 1,000 & 1,000 & 1,000 & 1,000 \\
\hline 6 & 1,000 & 1,000 & 1,000 & 1,000 & 1,000 & 0.999 \\
\hline 7 & 1,000 & 1,000 & 1,000 & 1,000 & 1,000 & 1,000 \\
\hline 8 & 1,000 & 1,000 & 1,000 & 1,000 & 1,000 & 0.999 \\
\hline 9 & 1,000 & 1,000 & 1,000 & 1,000 & 1,000 & 1,000 \\
\hline 10 & 1,000 & 1,000 & 1,000 & 1,000 & 1,000 & 1,000 \\
\hline
\end{tabular}

W celu porównania postaci drgań własnych (odpowiadającym wektorom własnym) wyznaczonych dla modelu podstawowego (3) oraz dla modelu zredukowanego (9) wprowadzono miare w postaci ilorazu kolejnych współrzędnych wektorów własnych. Dla wektorów podobnych wartości tych ilorazów są sobie równe. Miary podobieństwa postaci drgań własnych odpowiadających kolejnym częstotliwościom drgań własnych dla wariantu modelu ${ }^{A} \mathbf{q}_{8}$ przedstawiono $\mathrm{w}$ tabeli 8, dla wariantu modelu ${ }^{A} \mathbf{q}_{6}$ W tabeli 9, a dla wariantu modelu ${ }^{A} \mathbf{q}_{4}$ w tabeli 10.

Macierz transformacji ${ }^{A} \mathbf{T}_{I I I 4}$ uzyskana przy zastosowaniu III metody dla wariantu redukcji do wektora współrzędnych uogólnionych ${ }^{A} \mathbf{q}_{4}$ ma postać:

$$
{ }^{A} \mathbf{T}_{I I I 4}=\left[\begin{array}{cccc}
1 & 0 & 0 & 0 \\
0 & 1 & 0 & 0 \\
0 & 0 & 1 & 0 \\
0 & 0 & 0 & 1 \\
15,40 & -12,91 & -5,61 & 4,13 \\
50,09 & -40,82 & -17,85 & 9,56 \\
94,71 & -76,75 & -33,25 & 16,22 \\
124,88 & -100,95 & -43,63 & 20,54 \\
114,78 & -92,77 & -40,07 & 18,80 \\
80,76 & -65,22 & -28,13 & 13,03
\end{array}\right]
$$

Miara podobieństwa postaci drgań własnych modelu podstawowego do postaci drgań własnych zredukowanego modelu ${ }^{4} 4$ przy zastosowaniu $I I I$ metody

Tabela 10

\begin{tabular}{|c|c|c|c|c|}
\hline$i$ & $\frac{{ }^{A} \psi_{1 i}}{{ }^{A} \psi_{I I I 41 i}}$ & $\frac{{ }^{A} \psi_{2 i}}{{ }^{A} \psi_{I I I 42 i}}$ & $\frac{{ }^{A} \psi_{3 i}}{{ }^{A} \psi_{I I I 3 i}}$ & $\frac{{ }^{A} \psi_{4 i}}{{ }^{A} \psi_{I I I 44 i}}$ \\
\hline 1 & 1,000 & 1,000 & 1,000 & 1,000 \\
\hline 2 & 1,000 & 1,000 & 1,000 & 1,000 \\
\hline 3 & 1,000 & 1,000 & 1,000 & 1,000 \\
\hline 4 & 1,000 & 1,000 & 1,000 & 1,000 \\
\hline 5 & 1,000 & 1,000 & 1,000 & 1,000 \\
\hline 6 & 1,000 & 1,000 & 1,000 & 1,000 \\
\hline 7 & 1,000 & 1,000 & 1,000 & 1,000 \\
\hline 8 & 1,000 & 1,000 & 1,000 & 1,000 \\
\hline 9 & 1,000 & 1,000 & 1,000 & 1,000 \\
\hline 10 & 1,000 & 1,000 & 1,000 & 1,000 \\
\hline
\end{tabular}

Po podstawieniu zredukowanych macierzy bezwładności ${ }^{A} \mathbf{M}_{I I I}$ oraz sztywności ${ }^{A} \mathbf{K}_{I I I}$ do równania (15) wyznaczono zera transmitancji badanych wariantów zredukowanych modeli, które zebrano w tabeli 11.

Po podstawieniu zredukowanych macierzy bezwładności ${ }^{B} \mathbf{M}_{I I I}$ oraz sztywności ${ }^{B} \mathbf{K}_{I I I}$ do równania na uogólniony problem własny (10) wyznaczono wartości własne i wektory własne. Częstotliwości odpowiadające wyznaczonym wartościom własnym zebrano $\mathrm{w}$ tabeli 12 - indeks $(k)$ przy ${ }^{B} \lambda^{(k)}$ oznacza numer iteracji.

Zera transmitancji modelu podstawowego oraz zredukowanych modeli ${ }^{A} \mathbf{q}_{8},{ }^{A} \mathbf{q}_{6} \operatorname{oraz}^{A} \mathbf{q}_{4}$ przy zastosowaniu $I I I$ metody

Tabela 11

\begin{tabular}{|c|c|c|c|c|c|c|c|c|c|c|}
\hline$j$ & \multicolumn{1}{c|}{$\zeta_{j}$} & ${ }^{A} \zeta_{\text {III8i }}^{(1)}$ & ${ }^{A} \zeta_{\text {III8i }}^{(2)}$ & ${ }^{A} \zeta_{\text {III8i }}^{(k)}$ & ${ }^{A} \zeta_{\text {III } 6 i}^{(1)}$ & ${ }^{A} \zeta_{\text {III } 6 i}^{(2)}$ & ${ }^{A} \zeta_{\text {III } 6 i}^{(k)}$ & ${ }^{A} \zeta_{I I I 4 i}^{(1)}$ & ${ }^{A} \zeta_{I I I 4 i}^{(2)}$ & ${ }^{A} \zeta_{I I I 4 i}^{(k)}$ \\
\hline 1 & 59,30 & 59,37 & 59,30 & 69,70 & 60,57 & 59,46 & 69,74 & 66,43 & 60,64 & 70,90 \\
\hline 2 & 119,87 & 121,14 & 120,11 & 134,93 & 134,54 & 126,88 & 134,98 & - & - & 137,05 \\
\hline 3 & 173,47 & 177,34 & 175,00 & 174,53 & - & - & 174,53 & 176,70 & 157,62 & 174,58 \\
\hline 4 & 180,46 & 180,66 & 180,51 & - & 180,35 & 180,32 & - & 190,44 & 182,30 & - \\
\hline 5 & 227,25 & 227,26 & 227,25 & 210,18 & 224,42 & 212,92 & 210,28 & - & - & - \\
\hline 6 & 242,42 & 246,88 & 245,80 & 239,42 & 229,24 & 228,03 & 239,45 & - & - & - \\
\hline 7 & 270,14 & 278,81 & 278,15 & 269,37 & - & - & -- & - & - & - \\
\hline 8 & 287,53 & - & - & 287,53 & - & - & - & - & - & - \\
\hline 9 & 406,26 & - & - & - & - & - & - & - & - & - \\
\hline
\end{tabular}


Częstotliwości drgań własnych [rad/s] modelu podstawowego oraz zredukowanych modeli ${ }^{B} \mathrm{q}_{8},{ }^{B} \mathrm{q}_{6}$ oraz ${ }^{B} \mathbf{q}_{4}$ przy zastosowaniu III metody

Tabela 12

\begin{tabular}{|c|c|c|c|r|r|r|r|r|r|r|}
\hline$i$ & $\lambda_{i}$ & ${ }^{B} \lambda_{\text {III8i }}^{(1)}$ & ${ }^{B} \lambda_{\text {III8i }}^{(2)}$ & ${ }^{\boldsymbol{B}} \lambda_{\text {III8i }}^{(k)}$ & ${ }^{\boldsymbol{B}} \lambda_{\text {III6i }}^{(1)}$ & ${ }^{B} \lambda_{\text {III } 6 i}^{(2)}$ & ${ }^{B} \lambda_{\text {III } 6 i}^{(k)}$ & ${ }^{B} \lambda_{\text {III } 4 i}^{(1)}$ & ${ }^{\boldsymbol{B}} \lambda_{\text {II } 4 i}^{(2)}$ & ${ }^{\boldsymbol{B}} \lambda_{\text {III4i }}^{(k)}$ \\
\hline 1 & 29,19 & 29,48 & 29,20 & 29,19 & 30,07 & 29,20 & 29,19 & 30,66 & 29,21 & 29,19 \\
\hline 2 & 101,64 & 108,36 & 102,70 & 101,64 & 111,72 & 103,15 & 101,64 & 115,93 & 103,80 & 101,64 \\
\hline 3 & 161,05 & - & 166,18 & 161,05 & - & - & 161,05 & - & - & 161,05 \\
\hline 4 & 175,04 & 171,78 & - & 175,04 & 188,45 & 176,97 & 175,04 & - & - & 175,04 \\
\hline 5 & 222,55 & 226,39 & 224,52 & 222,55 & - & - & 222,55 & - & 209,55 & - \\
\hline 6 & 241,37 & 239,38 & 235,54 & 241,37 & - & - & 241,37 & 234,57 & - & - \\
\hline 7 & 270,03 & 270,04 & 270,03 & 270,03 & 266,64 & 264,98 & - & - & - & - \\
\hline 8 & 287,53 & 287,41 & 287,22 & 287,53 & 283,44 & 281,44 & - & - & - & - \\
\hline 9 & 308,98 & - & - & - & - & - & - & - & 339,81 & - \\
\hline 10 & 406,26 & 406,26 & 406,25 & - & 406,04 & 405,59 & - & 368,54 & - & - \\
\hline
\end{tabular}

W celu porównania postaci drgań własnych (odpowiadającym wektorom własnym) wyznaczonych dla modelu podstawowego (3) oraz dla modelu zredukowanego (9) wprowadzono miarę w postaci ilorazu kolejnych współrzędnych wektorów własnych. Dla wektorów podobnych wartości tych ilorazów są sobie równe. Miary podobieństwa postaci drgań własnych odpowiadających kolejnym czestotliwościom drgań własnych dla wariantu modelu ${ }_{B}^{B} \mathbf{q}_{8}$ przedstawiono w tabeli 13, dla wariantu modelu ${ }^{B} \mathbf{q}_{6}$ W tabeli 14 , a dla wariantu modelu ${ }^{B} \mathbf{q}_{4}$ w tabeli 15.

Miara podobieństwa postaci drgań własnych modelu podstawowego do postaci drgań własnych zredukowanego modelu ${ }^{B} q_{8}$ przy zastosowaniu III metody

\begin{tabular}{|c|c|c|c|c|c|c|c|c|}
\hline$i$ & $\frac{{ }^{B} \psi_{1 i}}{{ }^{B} \psi_{I I I 81 i}}$ & $\frac{{ }^{B} \psi_{2 i}}{{ }^{B} \psi_{I I I 82 i}}$ & $\frac{{ }^{\boldsymbol{B}} \psi_{3 i}}{{ }^{\boldsymbol{B}} \psi_{I I I 83 i}}$ & $\frac{{ }^{B} \psi_{4 i}}{{ }^{B} \psi_{I I I 84 i}}$ & $\frac{{ }^{B} \psi_{5 i}}{{ }^{B} \psi_{I I I 85 i}}$ & $\frac{{ }^{B} \psi_{6 i}}{{ }^{B} \psi_{I I I 86 i}}$ & $\frac{{ }^{\boldsymbol{B}} \psi_{7 i}}{{ }^{\boldsymbol{B}} \psi_{I I I 87 i}}$ & $\frac{{ }^{B} \psi_{8 i}}{{ }^{B} \psi_{I I I 88 i}}$ \\
\hline 1 & 1,000 & 1,000 & 1,000 & 1,000 & 1,000 & 1,000 & 1,000 & 1,000 \\
\hline 2 & 1,000 & 1,000 & 1,000 & 1,000 & 1,000 & 1,000 & 0,999 & 0,838 \\
\hline 3 & 1,000 & 1,000 & 1,000 & 1,000 & 1,000 & 1,000 & 1,000 & 1,000 \\
\hline 4 & 1,000 & 1,000 & 1,000 & 1,000 & 1,000 & 1,000 & 1,000 & 1,000 \\
\hline 5 & 1,000 & 1,000 & 1,000 & 1,000 & 1,000 & 1,000 & 1,000 & 1,000 \\
\hline 6 & 1,000 & 1,000 & 1,000 & 1,000 & 1,000 & 1,000 & 1,000 & 1,000 \\
\hline 7 & 1,000 & 1,000 & 1,000 & 1,000 & 1,000 & 1,000 & 1,000 & 0,996 \\
\hline 8 & 1,000 & 1,000 & 1,000 & 1,000 & 1,000 & 1,000 & 1,000 & 1,000 \\
\hline 9 & 1,000 & 1,000 & 1,000 & 1,000 & 1,000 & 1,000 & 1,001 & 0,963 \\
\hline 10 & 1,000 & 1,000 & 1,000 & 1,000 & 1,000 & 1,000 & 1,000 & 1,005 \\
\hline
\end{tabular}

Miara podobieństwa postaci drgań wlasnych modelu podstawowego do postaci drgań własnych zredukowanego modelu ${ }^{B} q_{6}$ przy zastosowaniu $I I I$ metody

\begin{tabular}{|c|c|c|c|c|c|c|}
\hline$i$ & $\frac{{ }^{B} \psi_{1 i}}{{ }^{B} \psi_{I I I 61 i}}$ & $\frac{{ }^{B} \psi_{2 i}}{{ }^{B} \psi_{I I I 62 i}}$ & $\frac{{ }^{B} \psi_{3 i}}{{ }^{B} \psi_{I I I 63 i}}$ & $\frac{{ }^{B} \psi_{4 i}}{{ }^{B} \psi_{I I I 64 i}}$ & $\frac{{ }^{B} \psi_{5 i}}{{ }^{B} \psi_{I I I 65 i}}$ & $\frac{{ }^{B} \psi_{6 i}}{{ }^{B} \psi_{I I I 66 i}}$ \\
\hline 1 & 1,000 & 1,000 & 1,000 & 1,000 & 1,000 & 1,000 \\
\hline 2 & 1,000 & 1,000 & 1,000 & 1,000 & 1,000 & 1,000 \\
\hline 3 & 1,000 & 1,000 & 1,000 & 1,000 & 1,000 & 0,999 \\
\hline 4 & 1,000 & 1,000 & 1,000 & 1,000 & 1,000 & 0,999 \\
\hline 5 & 1,000 & 1,000 & 1,000 & 1,000 & 1,000 & 1,000 \\
\hline 6 & 1,000 & 1,000 & 1,000 & 1,000 & 1,000 & 1,000 \\
\hline 7 & 1,000 & 1,000 & 1,000 & 1,000 & 1,000 & 1,000 \\
\hline 8 & 1,000 & 1,000 & 1,000 & 1,000 & 1,000 & 1,000 \\
\hline 9 & 1,000 & 1,000 & 1,000 & 1,000 & 1,000 & 1,000 \\
\hline 10 & 1,000 & 1,000 & 1,000 & 1,000 & 1,000 & 1,000 \\
\hline
\end{tabular}

Miara podobieństwa postaci drgań wlasnych modelu podstawowego do postaci drgań wlasnych zredukowanego modelu ${ }^{B} q_{4}$ przy zastoso-

\begin{tabular}{|c|c|c|c|c|}
\hline \multirow{3}{*}{$i$} & \multicolumn{2}{|c|}{ waniu $I I I$ metody } & \multicolumn{2}{|r|}{ Tabela 15} \\
\hline & ${ }^{B} \psi_{1 i}$ & ${ }^{B} \psi_{2 i}$ & ${ }^{B} \psi_{3 i}$ & ${ }^{B} \psi_{4 i}$ \\
\hline & $\overline{{ }^{B} \psi_{I I I 41 i}}$ & $\overline{{ }^{B} \psi_{I I I 42 i}}$ & $\overline{{ }^{B} \psi_{I I I 43 i}}$ & $\overline{{ }^{B} \psi_{I I I 44 i}}$ \\
\hline 1 & 1,000 & 1,000 & 1,000 & 1,000 \\
\hline 2 & 1,000 & 1,000 & 1,000 & 1,000 \\
\hline 3 & 1,000 & 1,000 & 1,000 & 1,000 \\
\hline 4 & 1,000 & 1,000 & 1,000 & 1,000 \\
\hline 5 & 1,000 & 1,000 & 1,000 & 1,000 \\
\hline 6 & 1,000 & 1,000 & 1,000 & 1,000 \\
\hline 7 & 1,000 & 1,000 & 1,000 & 1,000 \\
\hline 8 & 1,000 & 1,000 & 1,000 & 1,000 \\
\hline 9 & 1,000 & 1,000 & 1,000 & 1,000 \\
\hline 10 & 1,000 & 1,000 & 1,000 & 1,000 \\
\hline
\end{tabular}


Zera transmitancji modelu podstawowego oraz zredukowanych modeli ${ }^{B} \mathrm{q}_{8},{ }^{B} \mathrm{q}_{6}$ oraz ${ }^{B} \mathrm{q}_{4} \operatorname{przy}$

zastosowaniu III metody

Tabela 16

\begin{tabular}{|c|c|c|c|c|c|c|c|c|c|c|}
\hline$j$ & $\zeta_{j}$ & ${ }^{B} \zeta_{I I I 8 i}^{(1)}$ & ${ }^{B} \zeta_{I I I 8 i}^{(2)}$ & ${ }^{B} \zeta_{I I I 8 i}^{(k)}$ & ${ }^{B} \zeta_{I I I 6 i}^{(1)}$ & ${ }^{B} \zeta_{I I I 6 i}^{(2)}$ & ${ }^{B} \zeta_{I I I 6 i}^{(k)}$ & ${ }^{B} \zeta_{I I I 4 i}^{(1)}$ & ${ }^{B} \zeta_{I I I 4 i}^{(2)}$ & ${ }^{B} \zeta_{I I I 4 i}^{(k)}$ \\
\hline 1 & 40,19 & 41,12 & 40,22 & 44,07 & 42,94 & 40,27 & 44,28 & 44,54 & 40,52 & 44,66 \\
\hline 2 & 125,93 & 136,27 & 128,03 & 135,43 & 140,69 & 129,50 & 135,91 & - & 141,90 & 136,84 \\
\hline 3 & 168,67 & - & - & 169,97 & - & - & 170,03 & 162,47 & - & 170,16 \\
\hline 4 & 202,00 & 201,30 & 197,90 & - & - & - & - & - & - & - \\
\hline 5 & 222,60 & 226,70 & 224,58 & 222,45 & 222,18 & 216,20 & 222,46 & - & - & - \\
\hline 6 & 248,87 & 247,29 & 244,76 & 230,98 & - & - & 232,19 & - & - & - \\
\hline 7 & 270,93 & 270,93 & 270,93 & 268,18 & 267,25 & 265,43 & - & 265,47 & 267,34 & - \\
\hline 8 & 290,80 & 290,72 & 290,59 & 281,62 & 287,72 & 286,19 & - & - & - & - \\
\hline 9 & 308,98 & - & - & - & - & - & - & - & - & - \\
\hline
\end{tabular}

Macierz transformacji ${ }^{B} \mathbf{T}_{I I I 4}$ uzyskana przy zastosowaniu III metody dla wariantu redukcji do wektora współrzędnych uogólnionych ${ }^{B} \mathbf{q}_{4}$ ma postać:

$$
{ }^{B} \mathbf{T}_{I I I 4}=\left[\begin{array}{cccc}
1 & 0 & 0 & 0 \\
0 & 1 & 0 & 0 \\
0 & 0 & 1 & 0 \\
0 & 0 & 0 & 1 \\
1,94 & 0,01 & -1,03 & -0,15 \\
0,99 & 0,06 & -2,32 & 1,30 \\
-14,53 & 0,39 & 14,34 & 5,38 \\
-18,50 & 0,01 & 18,08 & 7,16 \\
34,49 & 1,25 & -37,47 & -9,86 \\
-86,71 & 0,14 & 93,49 & 25,36
\end{array}\right]
$$

Po podstawieniu zredukowanych macierzy bezwładności ${ }^{\boldsymbol{B}} \mathbf{M}_{I I I}$ oraz sztywności ${ }^{\boldsymbol{B}} \mathbf{K}_{I I I}$ do równania (15) wyznaczono zera transmitancji badanych wariantów zredukowanych modeli, które zebrano w tabeli 16.

\section{METODA}

W metodzie [8] do wyznaczania macierzy transformacji macierzy $\mathbf{t}$ wykorzystano pierwszy krok metody równoczesnej iteracji wektorowej [2], stosowanej w rozwiązywaniu uogólnionego zagadnienia własnego. Równanie charakteryzujące warunek ortogonalności (4) przy przyjętym podziale wektora zmiennych uogólnionych na zmienne podstawowe $\psi_{m}$ i zmienne pomocnicze $\psi_{s}$ przedstawiono $\mathrm{w}$ postaci:

$$
\left[\begin{array}{ll}
\boldsymbol{\Psi}_{m m}^{T} & \boldsymbol{\Psi}_{s m}^{T} \\
\boldsymbol{\Psi}_{m s}^{T} & \boldsymbol{\Psi}_{s s}^{T}
\end{array}\right]\left[\begin{array}{ll}
\mathbf{K}_{m m} & \mathbf{K}_{m s} \\
\mathbf{K}_{s m} & \mathbf{K}_{s s}
\end{array}\right]\left[\begin{array}{ll}
\boldsymbol{\Psi}_{m m} & \boldsymbol{\Psi}_{m s} \\
\boldsymbol{\Psi}_{s m} & \boldsymbol{\Psi}_{s s}
\end{array}\right]=\left[\begin{array}{cc}
\boldsymbol{\Lambda}_{m m} & \mathbf{0} \\
\mathbf{0} & \boldsymbol{\Lambda}_{s s}
\end{array}\right]
$$

Macierz transformacji t między zmiennymi $\psi_{m}$ i zmiennymi pomocniczymi $\psi_{s}$ ma postać (9). Aproksymację $i$-tą pierwszych $m$ wektorów własnych oznaczono macierzą $\boldsymbol{\Psi}_{m}^{(i)}$, którą przedstawiono w postaci:

$$
\boldsymbol{\Psi}_{m}^{(i)}=\left[\begin{array}{l}
\boldsymbol{\Psi}_{m m}^{(i)} \\
\boldsymbol{\Psi}_{s m}^{(i)}
\end{array}\right]=\left[\begin{array}{c}
\mathbf{I}_{m m} \\
\mathbf{t}^{(i)}
\end{array}\right] \boldsymbol{\Psi}_{m m}^{(i)}
$$

gdzie macierz $\mathbf{t}^{(i)}$ jest określona równaniem:

$$
\mathbf{t}^{(i)}=\boldsymbol{\Psi}_{s m}^{(i)}\left(\boldsymbol{\Psi}_{m m}^{(i)}\right)^{-1}
$$

W celu wyznaczenia kolejnej aproksymacji macierzy $\boldsymbol{\Psi}_{m}^{(i+1)}$ zastosowano pierwszy etap metody równoczesnej iteracji wektorowej wyznaczając podprzestrzeń $\mathbf{X}_{m}^{(i+1)}$

$$
\mathbf{X}_{m}^{(i+1)}=\mathbf{C} \boldsymbol{\Psi}_{m}^{(i)}
$$

gdzie macierz $\mathbf{C}$ ma postać:

$$
\mathbf{C}=\mathbf{K}^{-1} \mathbf{M}
$$

Stwierdzono, że drugi etap metody, związany z procesem ortonormalizacji nie wpływa na postać macierzy transformacji t. W związku z tym, kolejną aproksymację macierzy $\mathbf{t}^{(i+1)}$ wyrażono związkiem:

$$
\mathbf{t}^{(i+1)}=\mathbf{X}_{s m}^{(i+1)}\left(\mathbf{X}_{m m}^{(i+1)}\right)^{-1}
$$

Przedstawiając wyrażenie (51) w postaci odpowiadającej równaniu (48) i uwzględniając (49) uzyskano zależność:

$$
\left[\begin{array}{l}
\mathbf{X}_{m m}^{(i+1)} \\
\mathbf{X}_{s m}^{(i+1)}
\end{array}\right]=\left[\begin{array}{ll}
\mathbf{C}_{m m} & \mathbf{C}_{m s} \\
\mathbf{C}_{s m} & \mathbf{C}_{s s}
\end{array}\right]\left[\begin{array}{c}
\mathbf{I} \\
\mathbf{t}^{(i)}
\end{array}\right] \boldsymbol{\Psi}_{m m}^{(i)}
$$

Po podstawieniu wielkości $\mathbf{X}_{m m}^{(i+1)}$ oraz $\mathbf{X}_{s m}^{(i+1)}$ wyznaczonych ze związku (54) do równania (53) uzyskano wyrażenie na $i+1$-szą iterację macierzy transformacji $\mathbf{t}^{(i+1)}$ :

$$
\mathbf{t}_{I V}^{(i+1)}=\left(\mathbf{C}_{s m}+\mathbf{C}_{s s} \mathbf{t}_{I V}^{(i)}\right)\left(\mathbf{C}_{m m}+\mathbf{C}_{m s} \mathbf{t}_{I V}^{(i)}\right)^{-1}
$$

Macierz transformacji $\mathbf{t}^{(0)}$ dla pierwszego kroku iteracji ma postać:

$$
\mathbf{t}_{I V}^{(0)}=\mathbf{C}_{s m} \mathbf{C}_{m m}^{-1}
$$

Zredukowaną macierz sztywności $\mathbf{K}_{I V}$ zapisano równaniem:

$$
\mathbf{K}_{I V}^{(i+k)}=\mathbf{K}_{m m}+\left(\mathbf{t}_{I V}^{(i+k)}\right)^{T} \mathbf{K}_{s m}+\mathbf{K}_{m s} \mathbf{t}_{I V}^{(i+k)}+\left(\mathbf{t}_{I V}^{(i+k)}\right)^{T} \mathbf{K}_{s s} \mathbf{t}_{I V}^{(i+k)}
$$

a zredukowaną macierz bezwładności $\mathbf{M}_{I V}$ zapisano równaniem:

$\mathbf{M}_{I V}^{(i+k)}=\mathbf{M}_{m m}+\left(\mathbf{t}_{I V}^{(i+k)}\right)^{T} \mathbf{M}_{s m}+\mathbf{M}_{m s} \mathbf{t}_{I V}^{(i+k)}+\left(\mathbf{t}_{I V}^{(i+k)}\right)^{T} \mathbf{M}_{s s} \mathbf{t}_{I V}^{(i+k)}$

Jako warunek zakończenia procedury iteracyjnej przyjęto spełnienie nierówności: 


$$
\left|\frac{\lambda_{j}^{(i+k)}-\lambda_{j}^{(i)}}{\lambda_{j}^{(i+k)}}\right|<\varepsilon_{j} \text { dla } j=1,2, \ldots, m
$$

gdzie $\varepsilon_{j}$ jest zadaną wartością determinującą dokładność wyników.

Po podstawieniu zredukowanych macierzy bezwładności ${ }^{A} \mathbf{M}_{V V}$ i ${ }^{B} \mathbf{M}_{V V}$ oraz sztywności ${ }^{A} \mathbf{K}_{V V}$ i ${ }^{B} \mathbf{K}_{I V}$ do równania na uogólniony problem własny (10) wyznaczono wartości własne i wektory własne. Częstotliwości odpowiadające wyznaczonym wartościom własnym zebrano w tabeli 17 - indeks (1) przy $\lambda^{(1)}$ oznacza numer iteracji.
W celu porównania postaci drgań własnych (odpowiadającym wektorom własnym) wyznaczonych dla modelu podstawowego (3) oraz dla modelu zredukowanego (9) wprowadzono miarę $\mathrm{w}$ postaci ilorazu kolejnych współrzędnych wektorów własnych. Dla wektorów podobnych wartości tych ilorazów są sobie równe. Miary podobieństwa postaci drgań własnych odpowiadających kolejnym częstotliwościom drgań własnych dla wariantu modelu ${ }^{A} \mathbf{q}_{8}$ przedstawiono w tabeli 18, dla wariantu modelu ${ }^{A} \mathbf{q}_{6}$ w tabeli 19 , a dla wariantu modelu ${ }^{A} \mathbf{q}_{4}$ W tabeli 20.

Częstotliwości drgań własnych [rad/s] modelu podstawowego oraz wariantów zredukowanych modeli ${ }^{A} \mathbf{q}_{8},{ }^{A} \mathbf{q}_{6},{ }^{A} \mathbf{q}_{4},{ }^{B} \mathbf{q}_{8},{ }^{B} \mathbf{q}_{6}$ oraz ${ }^{B} \mathbf{q}_{4}$ przy zastosowaniu $I V$ metody

\begin{tabular}{|c|c|c|c|c|c|c|c|c|c|c|}
\hline$i$ & $\lambda_{I V i}$ & ${ }^{A} \lambda^{(1)}{ }_{I V 8 i}$ & ${ }^{B} \lambda^{(1)}{ }_{I V 8 i}$ & ${ }^{A, B} \lambda_{I V 8 i}$ & ${ }^{A} \lambda^{(1)}{ }_{I V 6 i}$ & ${ }^{B} \lambda^{(1)}{ }_{I V 6 i}$ & ${ }^{A, B} \lambda_{I V G i}$ & ${ }^{A} \lambda^{(1)}{ }_{I V 4 i}$ & ${ }^{B} \lambda^{(1)}{ }_{I V 4 i}$ & ${ }^{A, B} \lambda_{I V 4 i}$ \\
\hline 1 & 29,19 & 29,19 & 29,48 & 29,19 & 29,26 & 30,07 & 29,19 & 29,64 & 30,66 & 29,19 \\
\hline 2 & 101,64 & 102,43 & 108,36 & 101,64 & 112,52 & 111,72 & 101,64 & 156,20 & 115,93 & 101,64 \\
\hline 3 & 161,05 & 163,03 & 171,78 & 161,05 & 168,50 & 188,45 & 161,05 & 177,01 & 234,57 & 161,05 \\
\hline 4 & 175,04 & 177,52 & 226,39 & 175,04 & 222,42 & 266,64 & 175,04 & 308,69 & 368,54 & 175,04 \\
\hline 5 & 222,55 & 222,62 & 239,38 & 222,55 & 224,44 & 283,44 & 222,55 & - & - & - \\
\hline 6 & 241,37 & 245,82 & 270,04 & 241,37 & 308,96 & 406,04 & 241,37 & - & - & - \\
\hline 7 & 270,03 & 278,79 & 287,41 & 270,03 & - & - & - & - & - & - \\
\hline 8 & 287,53 & 308,98 & 406,26 & 287,53 & - & - & - & - & - & - \\
\hline 9 & 308,98 & & & - & & & - & & & - \\
\hline 10 & 406,26 & & & - & & & - & & & - \\
\hline
\end{tabular}

Miara podobieństwa postaci drgań własnych modelu podstawowego do postaci drgań wlasnych zredukowanego modelu ${ }^{A} q_{8}$ przy zastosowaniu $I V$ metody

\begin{tabular}{|c|r|r|r|r|r|r|r|r|}
\hline$i$ & ${ }^{A} \psi_{I V 1 i}$ & ${ }^{A} \psi_{I V 2 i}$ & ${ }^{A} \psi_{I V 3 i}$ & ${ }^{A} \psi_{I V 4 i}$ & ${ }^{A} \psi_{I V 5 i}$ & ${ }^{A} \psi_{I V 6 i}$ & ${ }^{A} \psi_{I V 7 i}$ & ${ }^{A} \psi_{I V 8 i}$ \\
\hline${ }^{A} \psi_{I V 81 i}$ & ${ }^{A} \psi_{I V 82 i}$ & ${ }^{A} \psi_{I V 83 i}$ & ${ }^{A} \psi_{I V 84 i}$ & ${ }^{A} \psi_{I V 85 i}$ & ${ }^{A} \psi_{I V 86 i}$ & ${ }^{A} \psi_{I V 87 i}$ & ${ }^{A} \psi_{I V 88 i}$ \\
\hline 2 & 1,000 & 1,000 & 1,000 & 1,000 & 1,000 & 1,000 & 0,999 & 0,158 \\
\hline 3 & 1,000 & 1,000 & 1,000 & 1,000 & 1,000 & 1,000 & 1,000 & 0,489 \\
\hline 4 & 1,000 & 1,000 & 1,000 & 1,000 & 1,000 & 1,000 & 1,001 & 1,168 \\
\hline 5 & 1,000 & 1,000 & 1,000 & 1,000 & 1,000 & 1,000 & 1,000 & 0,908 \\
\hline 6 & 1,000 & 1,000 & 1,000 & 1,000 & 1,000 & 1,000 & 1,000 & 1,000 \\
\hline 7 & 1,000 & 1,000 & 1,000 & 1,000 & 1,000 & 1,000 & 1,000 & 1,005 \\
\hline 8 & 1,000 & 1,000 & 1,000 & 1,000 & 1,000 & 1,000 & 1,000 & 0,999 \\
\hline 9 & 1,000 & 1,000 & 1,000 & 1,000 & 1,000 & 1,000 & 1,000 & 1,000 \\
\hline 10 & 1,000 & 1,000 & 1,000 & 1,000 & 1,000 & 1,000 & 1,000 & 0,999 \\
\hline
\end{tabular}

Miara podobieństwa postaci drgań własnych modelu podstawowego do postaci drgań własnych zredukowanego modelu ${ }^{A} \mathrm{q}_{6}$ przy zastosowaniu $I V$ metody

Tabela 19

\begin{tabular}{|r|r|r|r|r|r|r|}
\hline$i$ & ${ }^{A} \psi_{I V 1 i}$ & ${ }^{A} \psi_{I V 2 i}$ & ${ }^{A} \psi_{I V 3 i}$ & ${ }^{A} \psi_{I V 4 i}$ & ${ }^{A} \psi_{I V 5 i}$ & ${ }^{A} \psi_{I V 6 i}$ \\
\hline${ }^{A} \psi_{I V 61 i}$ & ${ }^{A} \psi_{I V 62 i}$ & ${ }^{A} \psi_{I V 63 i}$ & ${ }^{A} \psi_{I V 64 i}$ & ${ }^{A} \psi_{I V 65 i}$ & ${ }^{A} \psi_{I V 66 i}$ \\
\hline 1 & 1,000 & 1,000 & 1,000 & 1,000 & 1,000 & 0,983 \\
\hline 2 & 1,000 & 1,000 & 1,000 & 1,000 & 1,000 & 1,037 \\
\hline 3 & 1,000 & 1,000 & 1,000 & 1,000 & 1,000 & 1,001 \\
\hline 4 & 1,000 & 1,000 & 1,000 & 1,000 & 1,000 & 0,997 \\
\hline 5 & 1,000 & 1,000 & 1,000 & 1,000 & 1,000 & 1,001 \\
\hline 6 & 1,000 & 1,000 & 1,000 & 1,000 & 1,001 & 0,996 \\
\hline 7 & 1,000 & 1,000 & 1,000 & 1,000 & 1,002 & 1,042 \\
\hline 8 & 1,000 & 1,000 & 1,000 & 1,000 & 1,000 & 0,991 \\
\hline 9 & 1,000 & 1,000 & 1,000 & 1,000 & 1,002 & 1,002 \\
\hline 10 & 1,000 & 1,000 & 1,000 & 1,000 & 1,005 & 1,011 \\
\hline
\end{tabular}


Miara podobieństwa postaci drgań własnych modelu podstawowego do postaci drgań własnych zredukowanego modelu ${ }^{A} \mathbf{q}_{4}$ przy zastosowaniu IV metody

\begin{tabular}{|c|r|r|r|r|}
\multicolumn{7}{|c}{$I V$ metody } & \multicolumn{2}{c|}{ Tabela 20 } \\
\hline$i$ & ${ }^{A} \psi_{I V 1 i}$ & ${ }^{A} \psi_{I V 2 i}$ & ${ }^{A} \psi_{I V 3 i}$ & ${ }^{A} \psi_{I V 4 i}$ \\
& ${ }^{A} \psi_{I V 41 i}$ & ${ }^{A} \psi_{I V 42 i}$ & ${ }^{A} \psi_{I V 43 i}$ & ${ }^{A} \psi_{I V 44 i}$ \\
\hline 1 & 1,000 & 1,000 & 0,999 & 1,010 \\
\hline 2 & 1,000 & 1,000 & 0,999 & 1,001 \\
\hline 3 & 1,000 & 1,000 & 1,000 & 0,999 \\
\hline 4 & 1,000 & 1,000 & 0,997 & 0,990 \\
\hline 5 & 1,000 & 1,000 & 1,000 & 1,003 \\
\hline 6 & 1,000 & 1,000 & 0,999 & 0,999 \\
\hline 7 & 1,000 & 1,000 & 0,999 & 0,990 \\
\hline 8 & 1,000 & 1,000 & 1,000 & 1,000 \\
\hline 9 & 1,000 & 1,000 & 1,000 & 1,000 \\
\hline 10 & 1,000 & 1,000 & 1,000 & 1,001 \\
\hline
\end{tabular}

Macierz transformacji ${ }^{A} \mathbf{T}_{I V 4}$ uzyskana przy zastosowaniu $I V$ metody dla wariantu redukcji do wektora współrzędnych uogólnionych ${ }^{A} \mathbf{q}_{4}$ ma postać:

$$
{ }^{A} \mathbf{T}_{I V 4}=\left[\begin{array}{cccc}
1 & 0 & 0 & 0 \\
0 & 1 & 0 & 0 \\
0 & 0 & 1 & 0 \\
0 & 0 & 0 & 1 \\
1,94 & 0,01 & -1,03 & -0,15 \\
0,92 & 0,06 & -2,24 & 1,32 \\
-14,22 & 0,39 & 13,99 & 5,29 \\
-18,12 & 0,01 & 17,66 & 7,06 \\
33,28 & 1,24 & -36,13 & -9,52 \\
-83,77 & 0,16 & 90,25 & 24,55
\end{array}\right]
$$

W celu porównania postaci drgań własnych (odpowiadającym wektorom własnym) wyznaczonych dla modelu podstawowego (3) oraz dla modelu zredukowanego (9) wprowadzono miarę w postaci ilorazu kolejnych współrzędnych wektorów własnych. Dla wektorów podobnych wartości tych ilorazów są sobie równe. Miary podobieństwa postaci drgań własnych odpowiadających kolejnym częstotliwościom drgań własnych dla wariantu modelu ${ }_{B}^{B} \mathbf{q}_{8}$ przedstawiono w tabeli 21, dla wariantu modelu ${ }^{B} \mathbf{q}_{6}$ W tabeli 22 , a dla wariantu modelu ${ }^{B} \mathbf{q}_{4}$ w tabeli 23.

Miara podobieństwa postaci drgań własnych modelu podstawowego do postaci drgań wlasnych zredukowanego modelu ${ }^{B} q_{8}$ przy zastosowaniu $I V$ metody

Tabela 21

\begin{tabular}{|c|c|c|c|c|c|c|c|c|}
\hline$i$ & $\frac{{ }^{\boldsymbol{B}} \psi_{I V 1 i}}{{ }^{\boldsymbol{B}} \psi_{I V 81 i}}$ & $\frac{{ }^{B} \psi_{I V 2 i}}{{ }^{B} \psi_{I V 82 i}}$ & $\frac{{ }^{B} \psi_{I V 3 i}}{{ }^{B} \psi_{I V 83 i}}$ & $\frac{{ }^{\boldsymbol{B}} \psi_{I V 4 i}}{{ }^{\boldsymbol{B}} \psi_{I V 84 i}}$ & $\frac{{ }^{\boldsymbol{B}} \psi_{I V 5 i}}{{ }^{\boldsymbol{B}} \psi_{I V 85 i}}$ & $\frac{{ }^{B} \psi_{I V 6 i}}{{ }^{B} \psi_{I V 86 i}}$ & $\frac{{ }^{B} \psi_{I V 7 i}}{{ }^{B} \psi_{I V 87 i}}$ & $\frac{{ }^{\boldsymbol{B}} \psi_{I V 8 i}}{{ }^{\boldsymbol{B}} \psi_{I V 88 i}}$ \\
\hline 1 & 1,000 & 1,000 & 1,000 & 1,000 & 1,000 & 1,000 & 0,998 & 0,988 \\
\hline 2 & 1,000 & 1,000 & 1,000 & 1,000 & 0,999 & 0,997 & 0,989 & 0,479 \\
\hline 3 & 1,000 & 1,000 & 1,000 & 1,000 & 1,000 & 0,999 & 1,000 & 1,001 \\
\hline 4 & 1,000 & 1,000 & 1,000 & 1,000 & 1,000 & 1,000 & 1,000 & 1,000 \\
\hline 5 & 1,000 & 1,000 & 1,000 & 1,000 & 1,000 & 0,999 & 0,999 & 0,999 \\
\hline 6 & 1,000 & 1,000 & 1,000 & 1,000 & 1,000 & 1,000 & 1,000 & 1,000 \\
\hline 7 & 1,000 & 1,000 & 1,000 & 1,000 & 1,000 & 1,000 & 1,000 & 0,980 \\
\hline 8 & 1,000 & 1,000 & 1,000 & 1,000 & 1,000 & 1,000 & 1,000 & 1,000 \\
\hline 9 & 1,000 & 1,000 & 1,000 & 1,000 & 1,000 & 1,006 & 1,027 & 0,825 \\
\hline 10 & 1,000 & 1,000 & 1,000 & 1,000 & 1,000 & 1,000 & 1,010 & 1,030 \\
\hline
\end{tabular}

Miara podobieństwa postaci drgań własnych modelu podstawowego do postaci drgań własnych zredukowanego modelu ${ }^{B} \mathbf{q}_{6}$ przy zastosowaniu $I V$ metody

\begin{tabular}{|c|c|c|c|c|c|c|}
\hline \multicolumn{6}{|c|}{ przy zastosowaniu $I V$ metody } & Tabela 22 \\
\hline & ${ }^{B} \psi_{I V 1 i}$ & ${ }^{B} \psi_{I V 2 i}$ & ${ }^{B} \psi_{I V 3 i}$ & ${ }^{B} \psi_{I V 4 i}$ & ${ }^{B} \psi_{I V 5 i}$ & ${ }^{B} \psi_{I V 6 i}$ \\
\hline$t$ & $\overline{{ }^{B} \psi_{I V 61 i}}$ & ${ }^{B} \psi_{I V 62 i}$ & ${ }^{B} \psi_{I V 63 i}$ & ${ }^{B} \psi_{I V 64 i}$ & ${ }^{B} \psi_{I V 65 i}$ & $\overline{{ }^{B} \psi_{I V 66 i}}$ \\
\hline 1 & 1,000 & 1,000 & 1,000 & 1,000 & 0,996 & 0,995 \\
\hline 2 & 1,000 & 1,000 & 1,000 & 1,000 & 1,000 & 1,001 \\
\hline 3 & 1,000 & 1,000 & 1,000 & 1,000 & 0,990 & 0,989 \\
\hline 4 & 1,000 & 1,000 & 1,000 & 1,000 & 0,996 & 0,997 \\
\hline 5 & 1,000 & 1,000 & 1,000 & 1,000 & 1,000 & 1,047 \\
\hline 6 & 1,000 & 1,000 & 1,000 & 1,000 & 0,998 & 1,001 \\
\hline 7 & 1,000 & 1,000 & 1,000 & 1,000 & 1,000 & 1,001 \\
\hline 8 & 1,000 & 1,000 & 1,000 & 1,000 & 1,000 & 1,000 \\
\hline 9 & 1,000 & 1,000 & 1,000 & 1,000 & 1,000 & 1,000 \\
\hline 10 & 1,000 & 1,000 & 1,000 & 1,000 & 1,000 & 1,000 \\
\hline
\end{tabular}


Miara podobieństwa postaci drgań własnych modelu podstawowego do postaci drgań wlasnych zredukowanego modelu ${ }^{B} q_{4}$ przy zastosowaniu $I V$ metody

\begin{tabular}{|c|c|c|c|c|}
\hline & \\
\hline & ${ }^{\boldsymbol{B}} \psi_{I V 1 i}$ & ${ }^{B} \psi_{I V 2 i}$ & ${ }^{\boldsymbol{B}} \psi_{I V 3 i}$ & ${ }^{B} \psi_{I V 4 i}$ \\
\hline$l$ & ${ }^{B} \psi_{I V 41 i}$ & ${ }^{B} \psi_{I V 42 i}$ & ${ }^{B} \psi_{I V 43 i}$ & ${ }^{B} \psi_{I V 44 i}$ \\
\hline 1 & 1,000 & 1,000 & 1,000 & 0,998 \\
\hline 2 & 1,000 & 1,000 & 1,000 & 0,997 \\
\hline 3 & 1,000 & 1,000 & 1,000 & 0,996 \\
\hline 4 & 1,000 & 1,000 & 0,999 & 1,007 \\
\hline 5 & 1,000 & 1,000 & 1,000 & 0,999 \\
\hline 6 & 1,000 & 1,000 & 1,000 & 0,995 \\
\hline 7 & 1,000 & 1,000 & 1,000 & 1,001 \\
\hline 8 & 1,000 & 1,000 & 0,999 & 1,002 \\
\hline 9 & 1,000 & 1,000 & 1,000 & 1,000 \\
\hline 10 & 1,000 & 1,000 & 1,000 & 1,000 \\
\hline
\end{tabular}

Macierz transformacji ${ }^{\boldsymbol{B}} \mathbf{T}_{I V 4}$ uzyskana przy zastosowaniu $I V$ metody dla wariantu redukcji do wektora współrzędnych uogólnionych ${ }^{B} \mathbf{q}_{4}$ ma postać:

$$
{ }^{\boldsymbol{B}} \mathbf{T}_{I V 4}=\left[\begin{array}{cccc}
1 & 0 & 0 & 0 \\
0 & 1 & 0 & 0 \\
0 & 0 & 1 & 0 \\
0 & 0 & 0 & 1 \\
15,57 & -13,05 & -5,67 & 4,15 \\
49,94 & -40,70 & -17,80 & 9,54 \\
94,21 & -76,35 & -33,09 & 16,15 \\
124,06 & -100,29 & -43,36 & 20,43 \\
114,02 & -92,16 & -39,82 & 18,70 \\
80,18 & -64,76 & -27,94 & 12,96
\end{array}\right]
$$

Po podstawieniu zredukowanych macierzy bezwładności ${ }^{A} \mathbf{M}_{V}$ i ${ }^{B} \mathbf{M}_{V}$ oraz sztywności ${ }^{A} \mathbf{K}_{V}$ i ${ }^{B} \mathbf{K}_{V}$ do równania (15) wyznaczono zera transmitancji badanych wariantów zredukowanych modeli, które zebrano w tabeli 24.

\section{Omówienie wyników}

Ocenę wybranych do badań metod redukcji modelu układu przeprowadzono ze względu na zdolność metody do wygenerowania macierzy transformacji, umożliwiającej zbudowanie zredukowanego modelu reprezentowanego $\mathrm{z}$ wymaganą dokładnością zadanymi częstotliwościami drgań własnych, odpowiadającymi im postaciami drgań własnych oraz zerami transmitancji. Dla oceny wyników zastosowano miarę w postaci względnego błędu procentowego $\frac{\left|a_{i}-\hat{a}_{i}\right|}{a_{i}} 100 \%$, gdzie $a_{i}$ dotyczy układu podstawowego, a $\hat{a}_{i}$ dotyczy modelu zredukowanego. Dla metod iteracyjnych jako miare oceny przyjęto liczbe iteracji niezbędnych do osiagnięcia wyników obliczeń $\mathrm{z}$ wymaganą dokładnością. W ocenie metod uwzględniono również ich elastyczność $\mathrm{w}$ odniesieniu do zmiany struktury modelu wywołanej zmianą kolejności numeracji zmiennych uogólnionych.

\section{- Ocena metod redukcji odnośnie do częstotli- wości drgań własnych}

Pierwsza metoda nie umożliwia zbudowania zredukowanego modelu o wymaganych najniższych częstotliwościach drgań własnych. Na przykład (tabela 1), wyznaczona macierz transformacji dla wariantu ${ }^{A} \mathbf{q}_{6}$ umożliwia wygenerowanie pierwszej, drugiej, trzeciej, piątej, szóstej i dziewiątej częstotliwości drgań własnych, a dla wariantu ${ }^{\boldsymbol{B}} \mathbf{q}_{4}-$ pierwszej, drugiej, szóstej i dziesiątej. Największy względny błąd dla pierwszej częstotliwości ma wartość 5\%, a dla drugiej $14 \%$.

Druga metoda (tabela 4) również nie umożliwia odtworzenia wymaganych najniższych częstotliwości. Na przykład, wyznaczona macierz transformacji dla wariantu ${ }^{A} \mathbf{q}_{6}$ umożliwia wygenerowanie pierwszej, drugiej, czwartej, siódmej, ósmej i dziesiątej częstotliwości drgań własnych, a dla wariantu ${ }^{B} \mathbf{q}_{4}$ - pierwszej, drugiej, czwartej i ósmej. Pierwsza częstotliwość drgań własnych odtworzona jest w zredukowanym modelu bezbłędnie, a największy względny błąd dla drugiej częstotliwości ma wartość 9\%.

Zera transmitancji modelu podstawowego oraz wariantów zredukowanych modeli ${ }^{A} \mathbf{q}_{8},{ }^{A} \mathbf{q}_{6},{ }^{A} \mathbf{q}_{4},{ }^{B} \mathbf{q}_{8},{ }^{B} \mathbf{q}_{6}$ oraz ${ }^{B} \mathbf{q}_{4}$ przy zastosowaniu $I V$ metody

Tabela 24

\begin{tabular}{|c|c|c|c|c|c|c|c|c|}
\hline$j$ & $A \zeta_{j}$ & ${ }^{A} \zeta_{I V 8 j}$ & ${ }^{A} \zeta_{I V G j}$ & ${ }^{A} \zeta_{I V 4 j}$ & $B \zeta_{j}$ & ${ }^{B} \zeta_{I V 8 j}$ & ${ }^{B} \zeta_{I V G j}$ & ${ }^{B} \zeta_{I V 4 j}$ \\
\hline 1 & 59,30 & 69,70 & 69,73 & 70,90 & 40,19 & 44,07 & 44,28 & 44,66 \\
\hline 2 & 119,87 & 134,92 & 134,97 & 137,05 & 125,93 & 135,42 & 135,90 & 136,83 \\
\hline 3 & 173,47 & 174,53 & 174,53 & 174,59 & 168,67 & 169,97 & 170,03 & 170,15 \\
\hline 4 & 180,46 & - & - & - & 202,00 & - & - & - \\
\hline 5 & 227,25 & 210,17 & 210,25 & - & 222,60 & 222,45 & 222,46 & - \\
\hline 6 & 242,42 & 239,42 & 239,39 & - & 248,87 & 230,96 & 232,12 & - \\
\hline 7 & 270,14 & 269,37 & - & - & 270,93 & 268,16 & - & - \\
\hline 8 & 287,53 & 287,46 & - & - & 290,80 & 281,49 & - & - \\
\hline 9 & 406,26 & - & - & - & 308,98 & - & - & - \\
\hline
\end{tabular}


Trzecia metoda (tabela 7 dla wariantu $\boldsymbol{A}$, tabela 12 dla wariantu $\boldsymbol{B}$ ) oraz czwarta metoda (tabela 17) redukcji modelu układu umożliwiaja zbudowanie zredukowanego modelu o wymaganych najniższych częstotliwościach, przy zerowych błędach dla wszystkich częstotliwości.

\section{- Ocena metod redukcji odnośnie do postaci drgań wlasnych}

Modele zredukowane zbudowane za pomoca pierwszej metody odtwarzają macierz postaci drgań własnych niedokładnie (tabela 2). Największy względny błąd dla pierwszej postaci drgań własnych, dla wariantu ${ }^{A} \mathbf{q}_{4}$ wynosi $12 \%$ (na kierunku 10-tej współrzędnej uogólnionej), a dla wariantu ${ }^{B} \mathbf{q}_{4}$ wynosi $10 \%$ (na kierunku trzeciej współrzędnej uogólnionej). Postacie drgań własnych odpowiadające wyższym częstotliwościom drgań własnych obarczone są znacznie większymi błędami.

Modele zredukowane budowane za pomocą drugiej metody (tabela 5) odtwarzają dokładnie postać drgań własnych odpowiadającą pierwszej częstotliwości drgań własnych (największy względny błąd wynosi $1 \%$ ). Dla postaci odpowiadających wyższym częstotliwościom drgań własnych błąd jest znacznie większy.

Modele zredukowane zbudowane za pomocą trzeciej metody (tabele 8, 9 i 10 dla wariantu $\boldsymbol{A}$, tabele 13,14 i 15 dla wariantu $\boldsymbol{B}$ ) oraz czwartej metody (tabele 18 , 19 i 20 dla wariantu $\boldsymbol{A}$, tabele 21,22 i 23 dla wariantu B) redukcji odtwarzaja macierz postaci drgań własnych dokładnie. Jedynie postać drgań odpowiadająca ósmej częstotliwości drgań własnych odtworzona jest błędnie, przy czym największy względny błąd ma wartość 17\% (tabela 13) oraz 52\% (tabela 21) na kierunku wybranej współrzędnej uogólnionej.

\section{- Ocena metod redukcji odnośnie do zer trans- mitancji}

Zera transmitancji dla zredukowanych modeli wyznaczonych $\mathrm{z}$ zastosowaniem wszystkich wybranych metod redukcji są odtwarzane niedokładnie w odniesieniu do zer transmitancji modelu układu. Wartość pierwszego zera transmitancji zredukowanego modelu z zastosowaniem pierwszej metody (tabela 3) obarczona jest największym względnym błędem o wartości $12 \%$ dla wariantu ${ }^{A} \mathbf{q}_{4}$ oraz o wartości $28 \%$ dla wariantu ${ }^{B} \mathbf{q}_{6}$. Wartość pierwszego zera transmitancji zredukowanego modelu $\mathrm{z}$ zastosowaniem drugiej metody (tabela 6) obarczona jest największym względnym błędem o wartości $48 \%$ dla wariantu ${ }^{A} \mathbf{q}_{8}$ oraz o wartości $5 \%$ dla wariantu ${ }^{B} \mathbf{q}_{4}$. Wartość pierwszego zera transmitancji zredukowanego modelu $\mathrm{z}$ zastosowaniem trzeciej metody (tabela 11) obarczona jest największym względnym błędem o wartości 19\% dla wariantu ${ }^{A} \mathbf{q}_{4}$ oraz o wartości $11 \%$ dla wariantu ${ }^{B} \mathbf{q}_{4}$. Wartość pierwszego zera transmitancji zredukowanego modelu z zastosowaniem czwartej metody (tabela 16) obarczona jest największym względnym błędem o wartości $20 \%$ dla wariantu ${ }^{A} \mathbf{q}_{4}$ oraz o wartości $10 \%$ dla wariantu ${ }^{B} \mathbf{q}_{4}$.

\section{- Ocena metod redukcji odnośnie do liczby ite-} racji

Liczbę iteracji wykonanych przy badaniach zredukowanych modeli $z$ zastosowaniem trzeciej i czwartej metody zebrano w tabeli 25 . Jako warunek zakończenia procedury iteracyjnej przyjęto dla obu metod iteracyinych bład $\varepsilon_{i}=0,00001$.

\section{Liczba wykonanych iteracji dla warian- tów zredukowanych modeli ${ }^{A}{ }_{\mathbf{q}_{8},}{ }^{A} \mathbf{q}_{6},{ }^{A} \mathbf{q}_{4}$, ${ }^{B} \mathbf{q}_{8},{ }^{B} \mathbf{q}_{6}$ oraz ${ }^{B} \mathbf{q}_{4}$, przy zastosowaniu III $\mathbf{i}$}

\begin{tabular}{|c|r|r|r|r|r|r|}
\hline \multicolumn{1}{|c}{$\boldsymbol{I V}$ metody } & \multicolumn{3}{c|}{ Tabela 25} \\
metoda & ${ }^{A} \mathbf{q}_{8}$ & ${ }^{A} \mathbf{q}_{6}$ & ${ }^{A}{ }_{\mathbf{q}_{4}}$ & ${ }^{B}{ }_{\mathbf{q}_{8}}$ & ${ }^{B}{ }^{B} \mathbf{q}_{6}$ & ${ }^{B}{ }_{\mathbf{q}_{4}}$ \\
\hline$I I I$ & 119 & 39 & 24 & 26 & 41 & 24 \\
\hline$I V$ & 63 & 21 & 13 & 14 & 22 & 13 \\
\hline
\end{tabular}

- Ocena metod redukcji odnośnie do struktury zredukowanego modelu

Przeprowadzone badania numeryczne wykazały znaczny wpływ struktury zredukowanego modelu na wyniki obliczeń przy zastosowaniu pierwszej i drugiej metody redukcji. Stwierdzono również niewielki wpływ struktury zredukowanego modelu na wyniki obliczeń otrzymanych przy zastosowaniu trzeciej i czwartej metody redukcji.

\section{Podsumowanie}

W artykule przeprowadzono badania numeryczne dla dyskretnego modelu układu nośnego, których celem było określenie jakości stosowanych metod redukcji modelu na charakterystyki własne w postaci częstotliwości i postaci drgań własnych. Badaniom poddano również wpływ sposobu redukcji modelu układu na związki między wymuszeniem a odpowiedzią, charakteryzowane zerami transmitancji zredukowanego modelu. Efektem przeprowadzonej analizy wyników jest przyjęcie zalecenia odnośnie do stosowania $\mathrm{w}$ dynamicznej analizie modeli układów nośnych, iteracyjnych metod redukcji modelu (III metoda oraz $I V$ metoda). Stosujacc te metody uzyskano zgodne wartości częstotliwości drgań własnych modelu po redukcji oraz modelu podstawowego. Dokładność odwzorowania postaci drgań własnych zależy od zastosowanej metody oraz rozmiaru zredukowanego modelu.

Stwierdzono istotny wpływ podziału wektora współrzędnych uogólnionych na współrzędne podstawowe i współrzędne pomocnicze (co determinuje strukturę zredukowanych macierzy sztywności i mas) na dokładność odwzorowania postaci drgań własnych.

Mankamentem stosowania metod iteracyjnych jest to, że zredukowane macierze mas i sztywności moga tracić sens fizyczny. 
Oryginalną częścią pracy było zbadanie wpływu redukcji modelu układu na zera transmitancji zredukowanego układu. Stwierdzono, że żadna $\mathrm{z}$ badanych metod nie gwarantuje uzyskania wystarczająco dokładnych wyników. Zadanie wyznaczenia zer transmitancji jest istotne w badaniach zależności między wymuszeniem a odpowiedzią układu. Badania w tym zakresie są kontynuowane $\mathrm{w}$ kierunku potwierdzenia przedstawionych wniosków oraz zaproponowania metod redukcji modelu, gwarantujących odpowiednią jakość uzyskiwanych wyników odnośnie do zer transmitancji zredukowanego modelu.

\section{Literatura}

[1] Barczak A.: Zera i bieguny transmitancji a częstotliwości antyrezonansowe $i$ rezonansowe układów nośnych pojazdów, Pojazdy Szynowe, $1 / 2005$.

[2] Bathe K. J.: Finite Element Procedures, Prentice-Hall, Englewood Cliffs, NJ, 1996.

[3] Friswell M. I., Garvey S. D., Penny J. E.: Model reduction using dynamic and Iterated IRS Techniques, Journal of Sound and Vibrations, Vol. 186(2), 1995.

[4] Guyan R. J.: Reduction of stiffness and mass matrices, AIAA, Vol. 3(2), 1965.

[5] Mottershead J. E.: Structural Modification for the Assignment of Zeros Using Measured Receptances, ASME Journal of Applied Mechanics, Vol. 68, 2001.

[6] Paz M.: Dynamic condensation method, AIAA, Vol. 22(5), 1984

[7] Yong X., Rongming L.: Improvement on the iterated IRS method for structural eigensolutions, Journal of Sound and Vibrations, Vol. 270, 2004.

[8] Zu-Qing Q., Zhi-Fang F.: An iterative method for dynamic condensation of structural matrices, Mechanical Systems and Signal Processing, Vol. 14(4), 2000.

[9] MATLAB, wersia 7.0.4. 